\title{
A full-scale in situ heating test for high-level nuclear waste disposal: observations, analysis and interpretation
}

\author{
A. GENS*, M. SÁNCheZ†, L. DO N. GuimarÃesł, E. E. Alonso*, A. Lloret*, \\ S. OLIVELLA*, M. V. VILLAR $\S$ and F. HUERTAS
}

\begin{abstract}
The paper describes the performance, observations and interpretation of a large-scale in situ heating test that simulates a disposal concept for heat-emitting, high-level nuclear waste. In the experiment, heaters are emplaced in the axis of a tunnel excavated in granite to simulate the heat production of radioactive waste. The test is fully instrumented, and attention is focused on the thermohydro-mechanical (THM) behaviour of the near-field region constituted by the compacted bentonite barrier surrounding the heater and the immediately adjacent rock. Interpretation of the test is assisted by the performance of a coupled numerical analysis based on a formulation that incorporates the relevant THM phenomena. Initial and boundary conditions for the analysis as well as material parameters are determined from an extensive programme of field and laboratory experiments. The paper presents and discusses the thermal, hydraulic and mechanical observations in the bentonite barrier and in the host rock. Special attention is paid to the progress of hydration in the barrier, to the effects of heating and vapour transport, and to the development of swelling pressures in the barrier. After five years of heating, one of the heaters was switched off and the experiment was partially dismantled, allowing the final state of the barrier to be observed directly. The numerical analysis performed has proved able to represent the progress of the experiment very satisfactorily. In addition, predictions concerning the final state of the clay barrier are very close to the observations obtained during dismantling. The performance and analysis of the in situ test have significantly enhanced the understanding of a complex THM problem and have proved the capability of the numerical formulation to provide adequate predictive capacity.
\end{abstract}

KEYWORDS: expansive soils; full-scale tests; numerical modelling; partial saturation; temperature effects
La présente communication décrit le déroulement d'un test d'échauffement in situ simulant un concept d'élimination de déchets nucléaires fortement radioactifs à émission de chaleur, ainsi que des observations sur ce test et son interprétation. Dans le cadre de cette expérience, des appareils de chauffage sont mis en place dans l'axe d'un tunnel creusé dans du granite, en simulant l'émission de chaleur de déchets radioactifs. Ce test est entièrement instrumenté, et se concentre sur le comportement thermo - hydromécanique (THM) de la région de champ proche constituée par la barrière de bentonite compactée entourant les appareils de chauffage et la roche adjacente. L'interprétation du test est assistée par l'exécution d'une analyse numérique accouplée, basée sur une formule incorporant les phénomènes THM correspondants. Les conditions initiales et limites de l'analyse, ainsi que des paramètres matériels, sont déterminés à partir d'un vaste programme d'expériences effectuées sur le terrain et en laboratoire. La présente communication présente et discute des observations thermiques, hydrauliques et mécaniques effectuées dans la barrière de bentonite, ainsi que dans la roche hôte. Elle se penche tout particulièrement sur l'évolution de l'hydratation dans la barrière, les effets du chauffage et du transport de la vapeur, et le développement de pressions d'expansion dans la barrière. Au bout d'une période de chauffage de cinq ans, on a arrêté un des appareils de chauffage et démantelé partiellement l'expérience, afin de pouvoir observer directement la situation finale de la barrière. L'analyse numérique effectuée s'est avérée en mesure de représenter de façon très satisfaisante l'évolution de cette expérience. En outre, les prédictions formulées sur l'état final de la barrière d'argile sont très proches des observations effectuées au cours du démantèlement. L'exécution et l'analyse du test effectué in situ ont renforcé considérablement les connaissances sur un problème THM complexe, et ont permis de démontrer la façon dont la formulation numérique est en mesure de fournir une capacité prédictive adéquate.

\section{INTRODUCTION}

In many countries employing nuclear power, deep geological storage or disposal is an intensively studied option for the long-term confinement of heat-emitting, high-level nuclear waste (HLW) (Gens, 2003). The construction of deep repositories will involve the excavation of a network of tunnels in

Manuscript received 8 May 2008; revised manuscript accepted 1 February 2009.

Discussion on this paper closes on 1 October 2009, for further details see p. ii.

* Department of Geotechnical Engineering and Geosciences,

Universitat Politècnica de Catalunya, Barcelona, Spain.

$\dagger$ University of Strathclyde, Glasgow, UK.

\$Universidade Federal de Pernambuco, Recife, Brazil.

$\S$ CIEMAT, Madrid, Spain.

- ENRESA, Madrid, Spain a suitable host rock a few hundred metres below the surface (Fig. 1). The canisters containing nuclear waste will be placed either in horizontal drifts or in vertical boreholes. Repository designs for HLW resort to the multi-barrier concept to achieve the required degree of waste isolation. This is based on placing several barriers, both natural and artificial, between the potentially harmful radionuclides and the biosphere. The natural barrier is fundamentally the host rock, and the artificial barriers are the solid matrix of the waste itself, the metallic canister enclosing the waste, and the backfill - the sealing material placed around the canisters to fill the cavities where they are placed (Fig. 2). This backfill, also called an 'engineered barrier', is often constructed using compacted expansive clay. Bentonite has generally been chosen because of its high swelling capacity, low permeability and favourable retardation properties.

The engineered clay barrier and adjacent host rock 


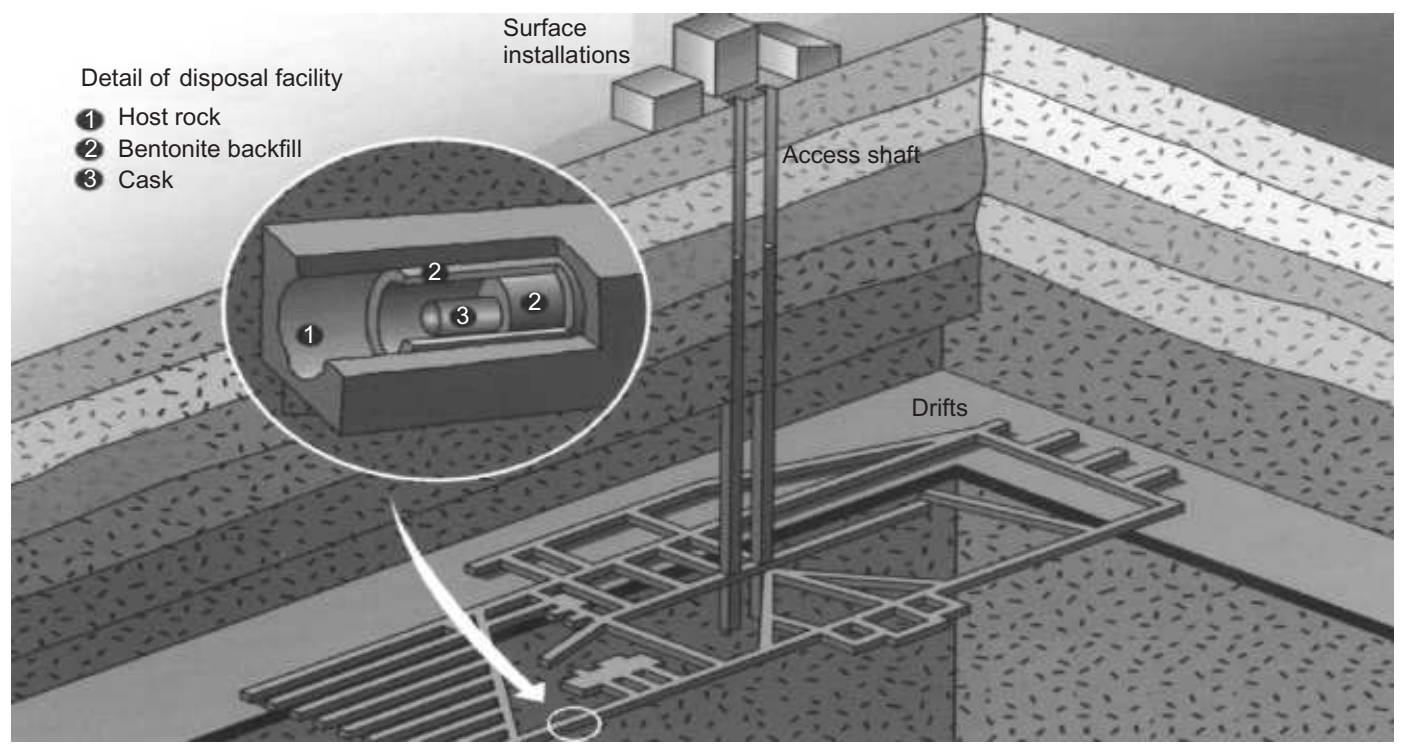

Fig. 1. Concentual scheme of deen geological repository for hioh-level nuclear waste

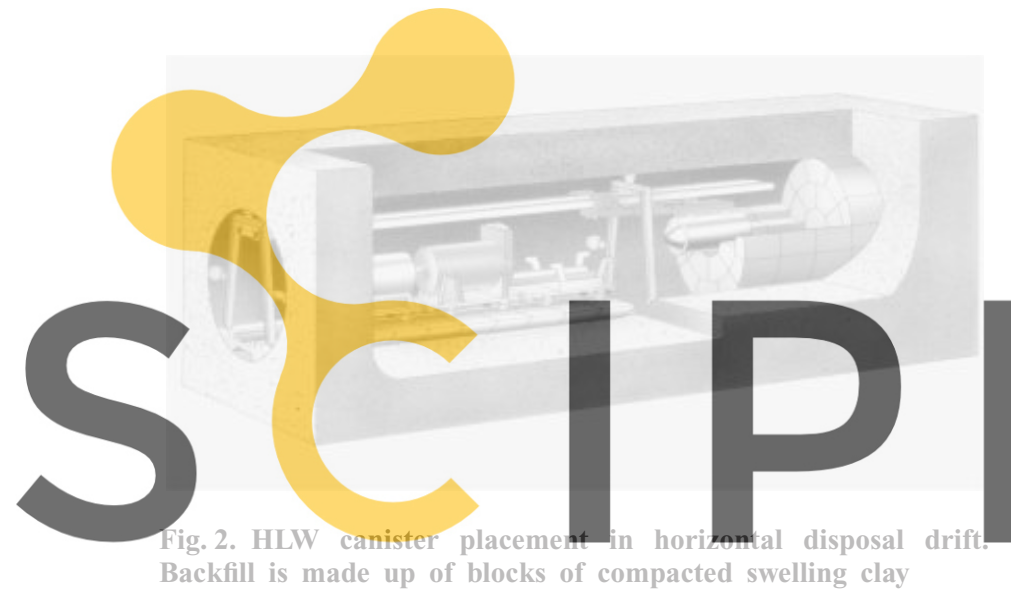

mechanics point of view, those in situ tests provide the opportunity not only to examine the behaviour of swelling clays under rather extreme but controlled conditions but also to validate, using field observations, coupled THM formulations and associated computer codes. Therefore the lessons learnt in those exercises have a wider scope of applicability,

\section{Register for free at https//www.scipedia.com to do} (usually called the 'near field') will be subjected to the heating effect of the nuclear waste, and also to various associated hydraulic and mechanical phenomena that interact in a complex way. In addition, compacted bentonite is initially unsaturated, and will therefore be subjected to hydration from the surrounding rock, triggering further coupled thermo-hydro-mechanical (THM) phenomena. In order to achieve a safe and robust repository design, it is necessary to have a good understanding of the processes that occur in the near field, and of their evolution over time. Given the importance of the problem, it has proved useful to perform large-scale and medium-scale heating tests simulating repository conditions in underground laboratories around the world (e.g. Pusch et al., 1985; Volckaert et al., 1996; Selvadurai, 1997; Dixon et al., 2002). Because of the low permeability of the materials involved, such experiments usually require long testing times, measured in years, in order to obtain meaningful results. The complexity of the phenomena involved, and of their interactions, implies that process understanding and interpretation of results are limited unless supported by suitable numerical models able to reproduce the main features of the test. Owing to the coupled nature of the THM interactions, coupled THM formulations are inevitably required.

In situ tests in underground laboratories are generally intensively instrumented, and often include a large amount of the independent data required to define the parameters of the coupled THM numerical model adequately. From the soil

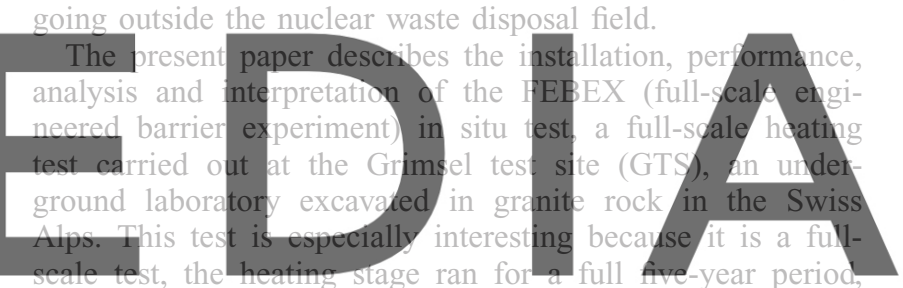

and the intensity of instrumentation and associated labora- 
circular tunnel was excavated in the GTS underground laboratory using a TBM machine (Fig. 3). The tunnel is $70.4 \mathrm{~m}$ long, and the final $17.4 \mathrm{~m}$ section was selected for the performance of the test. In the test area, two $4300 \mathrm{~W}$ heaters were placed in the axis of the horizontal drift. The heaters were $4.54 \mathrm{~m}$ long and $0.90 \mathrm{~m}$ in diameter, and were intended to simulate the release of heat by HLW. The space between the rock surface and the heaters was backfilled using blocks of compacted bentonite. The installation of the heaters was assisted by placing a liner between the heaters and the bentonite (Fig. 4). Finally, the test area was sealed with a $2.7 \mathrm{~m}$ long concrete plug. Fig. 5 shows a schematic layout of the test.

The host rock is good-quality Central Aare granite, crossed, in the test zone, by a lamprophyre dyke. The clay is a bentonite $\left(w_{\mathrm{L}}=98-106, w_{\mathrm{P}}=50-56\right)$, obtained from a quarry in the volcanic zone of Serrata de Nijar in Southern
Spain. It has high smectite content, in the range $88-96 \%$, with small and variable quantities of accessory minerals such as quartz, calcite and feldspars. The cation exchange capacity is $100-102 \mathrm{meq} / 100 \mathrm{~g}(42 \% \mathrm{Ca}, 33 \% \mathrm{Mg}, 23 \% \mathrm{Na}, 2 \%$ $\mathrm{K})$. The bentonite blocks were compacted to a dry density of $1.7 \mathrm{~g} / \mathrm{cm}^{3}$ at an average water content of $14.4 \%$. Because there were small gaps between blocks, and between the clay barrier and the rock, the overall dry density of the emplaced barrier was $1.6 \mathrm{~g} / \mathrm{cm}^{3}$.

The test is heavily instrumented: a total of 632 sensors were installed in the engineered barrier and in the rock. The instrumented bentonite sections are indicated in Fig. 5. The following parameters were measured: temperatures, relative humidity (total suction), pore water pressures, total pressures and displacements. Although the number and layout of instruments differed, depending on the section considered, Fig. 6 shows a typical instrumented section. Of special
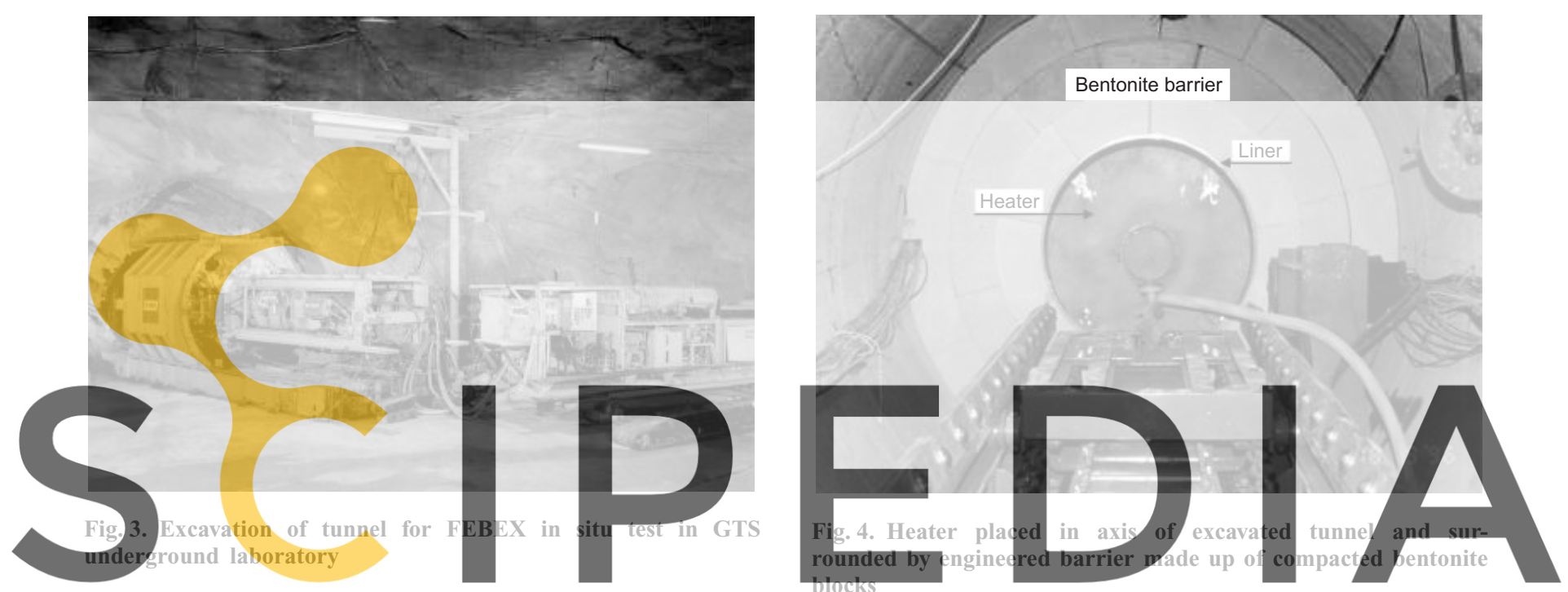

Register for free at https//www.scipedia.comp to download the version without the watermark

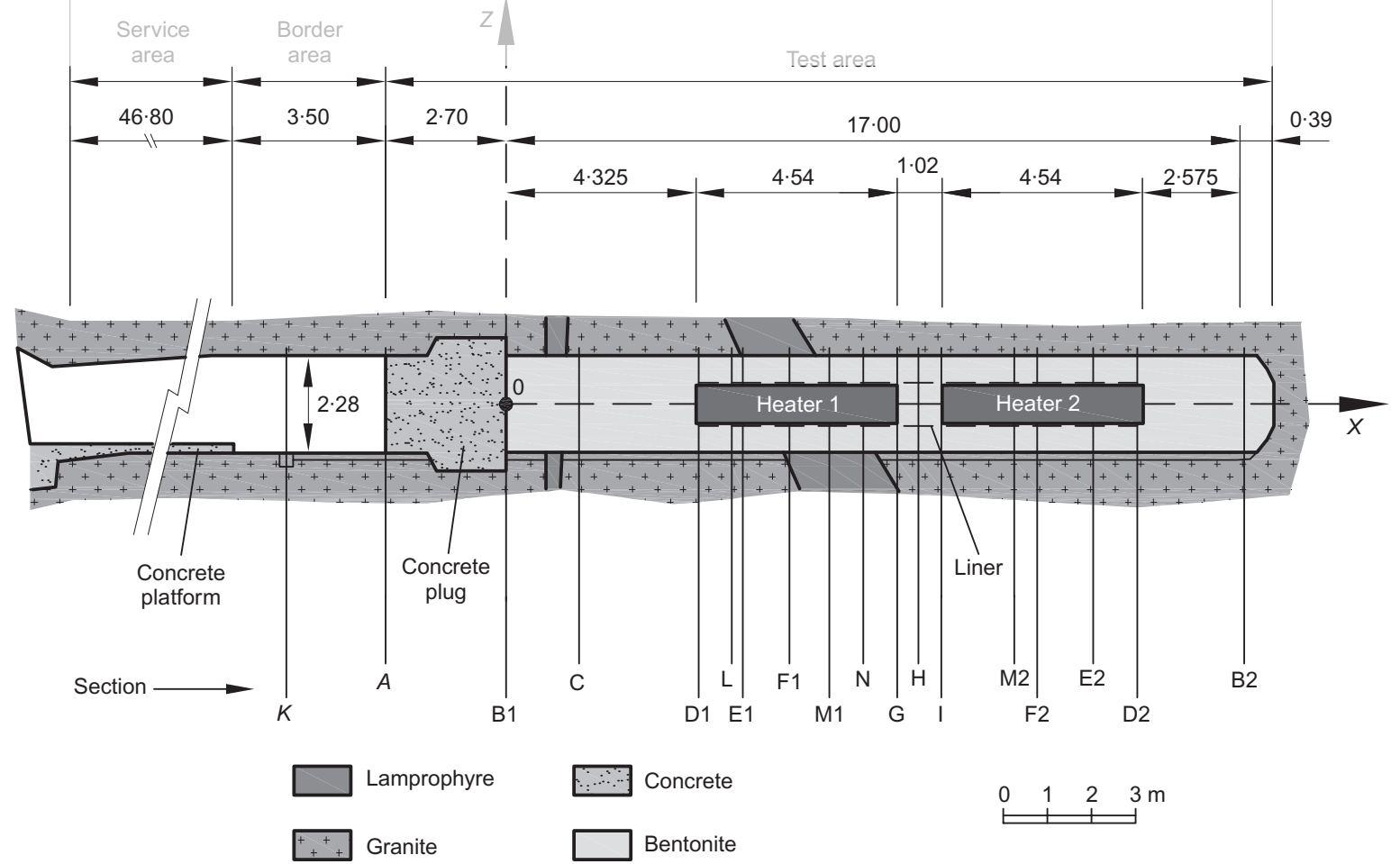

Fig. 5. Layout of FEBEX in situ test. Instrumented sections are indicated 


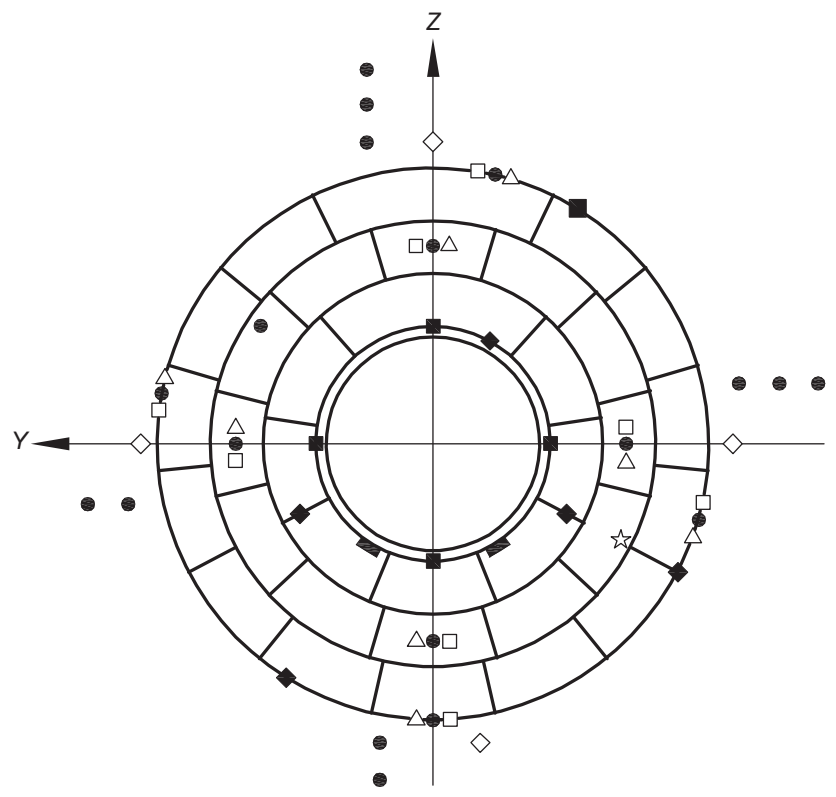

to measuring total suction. In addition, several boreholes were drilled into the rock prior to placement of the heaters and bentonite blocks in order to install monitoring devices (Fig. 8). Temperature, pore pressure, total pressure and displacements were observed in the rock.

After installation of the test, four months were allowed to elapse before the heaters were switched on. During this time there was some hydration of the barrier from the rock but, obviously, no thermal loading. During the heating stage the test was temperature controlled, with a prescribed maximum temperature of $100^{\circ} \mathrm{C}$ at the contact between liner and bentonite. To achieve this, the sequence of operations was as follows.

(a) The heaters were switched on at a constant power of $1200 \mathrm{~W}$ each for 20 days. The aim was to identify the thermal response of the system, and to adjust the control algorithm.

(b) Then the power of each heater was increased to $2000 \mathrm{~W}$, and kept constant until a temperature of $100^{\circ} \mathrm{C}$ at the contact between liner and bentonite was reached. This occurred after 33 davs

(c) Subsequently, the system operated under temperature control: that is, power was adjusted to keep a constant $100^{\circ} \mathrm{C}$ maximum temperature on the liner/barrier contact.

Figure 9 shows the evolution of the maximum temperature of the steel liner/bentonite contact and of the Heater 1 power during the early stages of the experiment. The heating stage
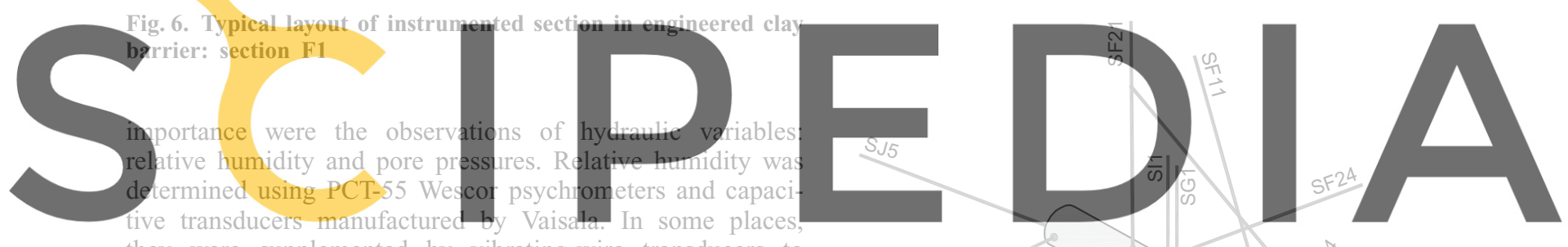

they were supplemented by vibrating-wire transducers to

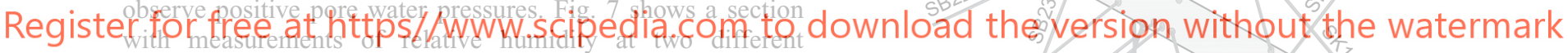
distances from the heater. At each location two instruments have been placed: a capacitive transducer and a psychrometer. Capacitive sensors proved to be much more robust and reliable than psychrometers. It should be noted that there is a direct relationship between relative humidity and total suction, given by Kelvin's equation (shown later). Therefore measuring relative humidity (and temperature) is equivalent

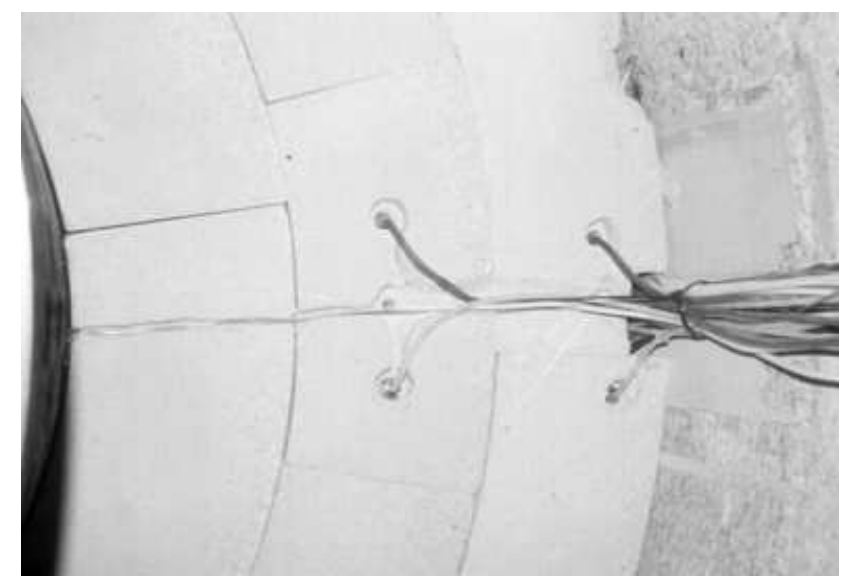

Fig. 7. Instruments for measurement of relative humidity at different distances from heater: capacitive sensors and psychrometers

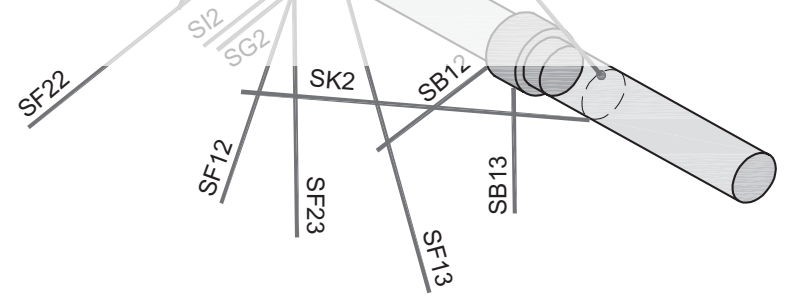

Fig. 8. Layout of boreholes drilled for monitoring host rock

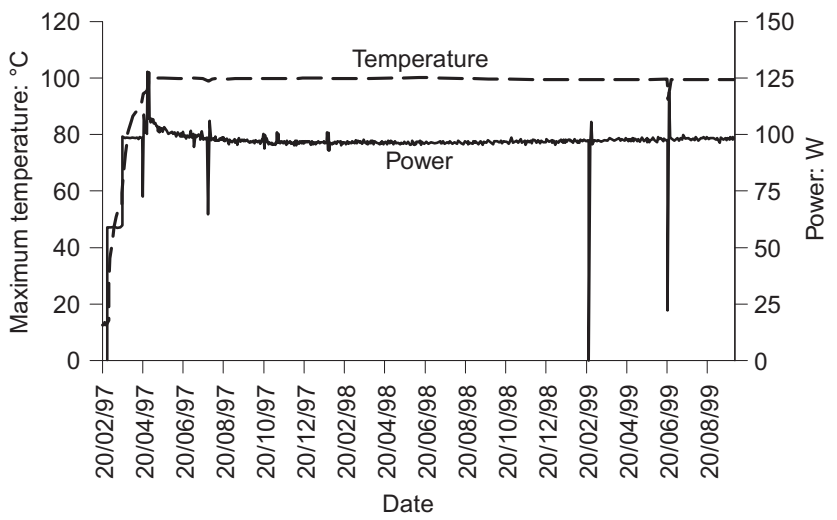

Fig. 9. Evolution of maximum temperature of steel liner and power in Heater 1 during early stages of experiment 
under this temperature-controlled condition lasted for exactly five years. Subsequently, the heaters were switched off and, after a cooling period, the experiment was partially dismantled. The dismantling phase is considered in more detail in the final part of the paper.

In addition to the in situ test, the FEBEX project also included the 'mock-up' test, a similar large-scale experiment, but performed in the laboratory. This test is outside the scope of this paper. Additional information on the full FEBEX project and its modelling is given in Huertas et al. (2006) and in Sánchez \& Gens (2006).

\section{COUPLED THM FORMULATION \\ THM processes}

It is envisaged that a significant number of coupled THM processes will occur in the engineered barrier during the test. Because of the similar conditions, it is also to be expected that the same processes will also occur in the operation of the real HLW waste repository when it is constructed (Gens et al., 2002). For reference, it is useful to anticipate, qualitatively, the key features of this THM scenario in order to identify the main characteristics of the required theoretical formulation.

The major actions that affect the bentonite barrier are heating and hydration from the surrounding rock. Fig. 10 shows, in a schematic way, some of the thermo-hydraulic processes occurring in the bentonite barrier and immediate adjacent rock. At the inner boundary, the barrier receives a very strong heat flux from the heaters. The dominant heat transfer mechanism is conduction through the three phases

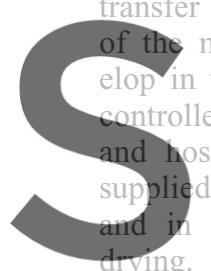
material. A temperature the near field, and heat d by the thermal conducti rock. In the inner zo strong heater results in The degree of saturatio
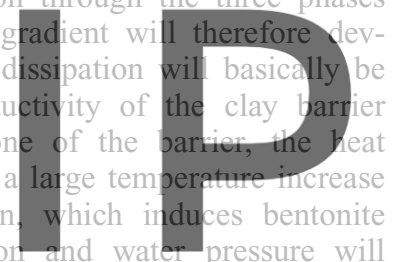

crease in water saturation. Vapour diffusion is a significant mechanism of water transfer, and it also contributes, but to a much lesser extent, to heat transport.

Owing to the high suction initially present in the unsaturated material that constitutes the backfill, hydration will occur, with water moving from the host rock towards the barrier. The distribution of water potential inside the clay barrier is strongly affected by the phenomena of bentonite drying and vapour transport, as described above. Hydration should eventually lead to saturation of the barrier, but full saturation times can be very long, owing to the low permeability of the bentonite and/or the host rock.

In addition to the thermo-hydraulic behaviour, there are also important mechanical phenomena occurring. Drying of the bentonite will cause shrinking of the material, whereas hydration will produce swelling, which may be quite pronounced in highly compacted bentonite barriers. Because the barrier is largely confined between the heater and the rock, the main result of hydration is the development of swelling pressures in a process quite akin to a swelling pressure test. The magnitude of the stresses developed is critically dependent on the emplacement density of the bentonite, and may reach values of several $\mathrm{MPa}$.

The crucial feature of the THM behaviour described is that all these phenomena are strongly coupled, interacting with each other in a complex manner. As an example, consider the phenomenon of vapour transport. Evaporation and condensation depend on the value of suction (a hydraulic variable) and temperature (a thermal variable). Transport itself is a mixture of advection and diffusion, and is influ-

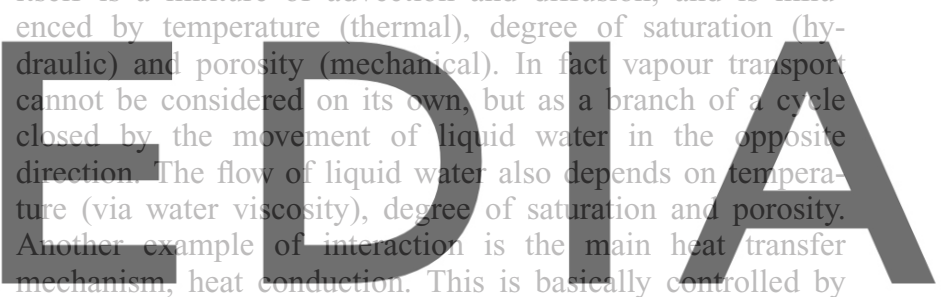

thermal conductivity, which, in turn, depends on degree of
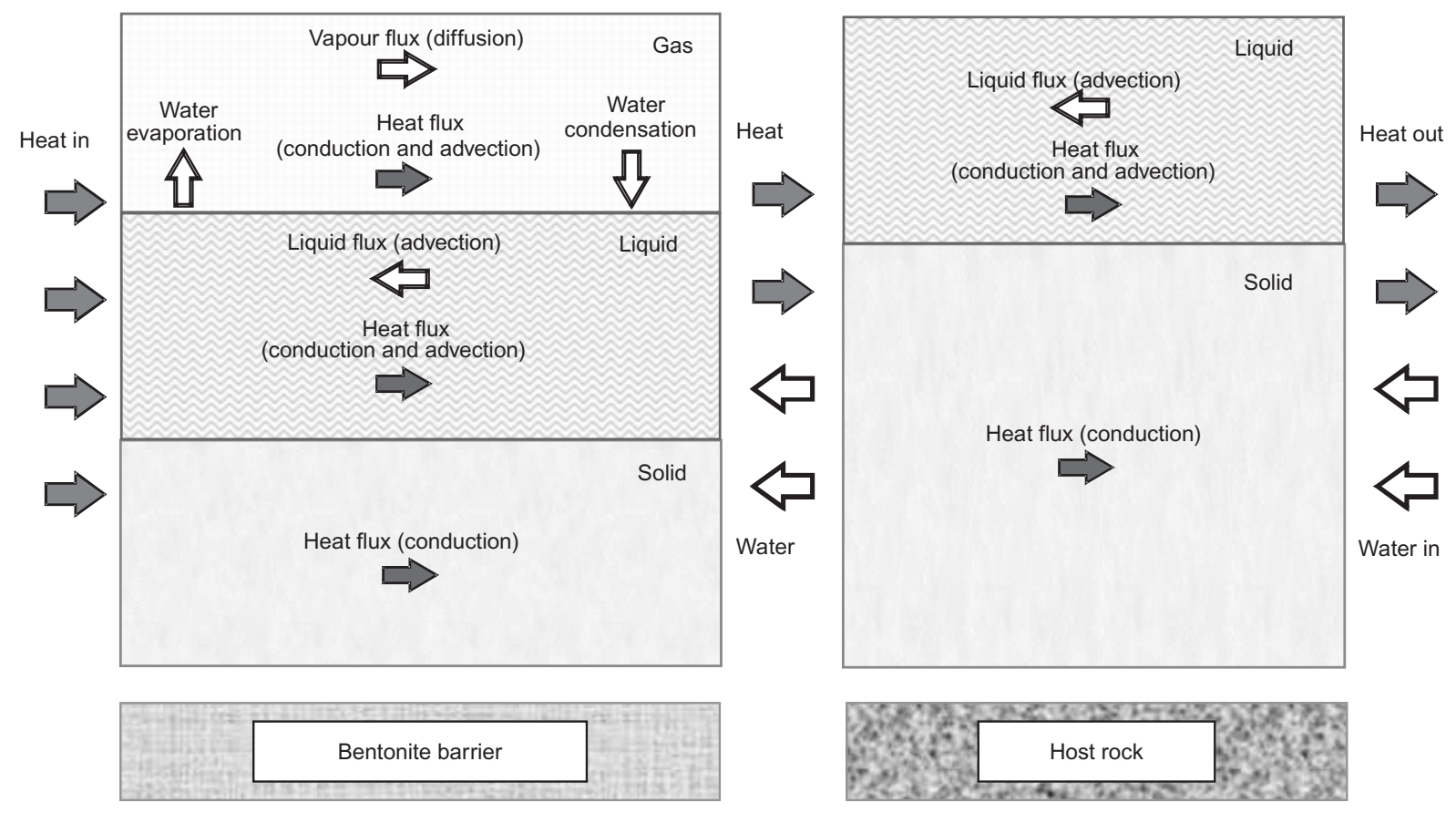

Fig. 10. Scheme of thermo-hydraulic processes in the near field 
complexity of THM behaviour increases further when the interaction of the bentonite barrier with the host rock is taken into account (Gens et al., 1998).

Therefore, in order to encompass the processes outlined above, the THM formulation should incorporate the following phenomena:

(a) heat transport

(i) heat conduction

(ii) heat advection (liquid water)

(iii) heat advection (water vapour)

(iv) heat advection (gaseous air)

(v) phase changes

(b) water flow

(i) liquid advection

(ii) water vapour diffusion

(c) air flow

(i) gas advection

(ii) dissolved air diffusion

(d) mechanical behaviour behaviour of porous materials dependent on stresses, suction and temperature.

\section{THM formulation: balance equations}

There have been a number of coupled THM formulations proposed (e.g. Gawin et al., 1995; Thomas \& He, 1995). The one used in this paper has been described previously (Olivella et al., 1994; Gens et al., 1998; Gens \& Olivella, 2000; Gens, 2007) and it will only be outlined herein. To establish the balance equations (a central feature of the formulation), the compositional approach is adopted. consist of balancing the species than the phases (solid, liquid change terms do not appea

\section{ich is particularly useful v} umed. The following conv equations defining the for

species (w for water and a for air) and subscripts refer to

Register por free solig thor liquid and g. for gas. Dry air is

the mineral species, because it has been assumed that it coincides with the solid phase. The notation used is listed at the end of the paper.

The mass balance of solid present in the medium is written as

$$
\frac{\partial}{\partial t}\left[\theta_{\mathrm{s}}(1-\phi)\right]+\nabla \cdot\left(\boldsymbol{j}_{\mathrm{s}}\right)=0
$$

From this equation, an expression for porosity variation is obtained as

$$
\frac{\mathrm{D}_{\mathrm{s}} \phi}{\mathrm{D} t}=\frac{1}{\theta_{\mathrm{s}}}\left[(1-\phi) \frac{\mathrm{D}_{\mathrm{s}} \theta_{\mathrm{s}}}{\mathrm{D} t}\right]+(1-\phi) \nabla \cdot \frac{\mathrm{d} \boldsymbol{u}}{\mathrm{d} t}
$$

Equation (2) expresses the variation of porosity caused by volumetric deformation and solid density variation. To obtain it, the material derivative with respect to the solid,

$$
\frac{\mathrm{D}_{\mathrm{s}}(\cdot)}{\mathrm{D} t}=\frac{\partial}{\partial t}+\frac{\mathrm{d} \boldsymbol{u}}{\mathrm{d} t} \cdot \nabla(\cdot)
$$

has been used.

Water is present in both liquid and gas phases. The total mass balance of water is expressed as

$$
\frac{\partial}{\partial t}\left(\theta_{1}^{\mathrm{w}} S_{1} \phi+\theta_{\mathrm{g}}^{\mathrm{w}} S_{\mathrm{g}} \phi\right)+\nabla \cdot\left(j_{1}^{\mathrm{w}}+j_{\mathrm{g}}^{\mathrm{w}}\right)=f^{\mathrm{w}}
$$

where $f^{\mathrm{w}}$ represents any external supply of water. The use of the material derivative leads to

$$
\begin{aligned}
\phi & \frac{\mathrm{D}_{\mathrm{s}}\left(\theta_{1}^{\mathrm{w}} S_{1}+\theta_{\mathrm{g}}^{\mathrm{w}} S_{\mathrm{g}}\right)}{\mathrm{D} t}+\left(\theta_{1}^{\mathrm{w}} S_{1}+\theta_{\mathrm{g}}^{\mathrm{w}} S_{\mathrm{g}}\right) \frac{\mathrm{D}_{\mathrm{s}} \phi}{\mathrm{D} t} \\
& +\left[\left(\theta_{1}^{\mathrm{w}} S_{1}+\theta_{\mathrm{g}}^{\mathrm{w}} S_{\mathrm{g}}\right) \phi\right] \nabla \cdot \frac{\mathrm{d} \boldsymbol{u}}{\mathrm{d} t} \\
& +\nabla \cdot\left(j_{1}^{\prime \mathrm{w}}+\boldsymbol{j}_{\mathrm{g}}^{\prime \mathrm{w}}\right)=f^{\mathrm{w}}
\end{aligned}
$$

Following the same approach, it is straightforward to obtain the mass balance of air equation taking into account that, although air is the main component of the gas phase, it may also be present in the liquid phase as dissolved air.

$$
\begin{aligned}
& \phi \frac{\mathrm{D}_{\mathrm{s}}\left(\theta_{1}^{\mathrm{a}} S_{1}+\theta_{\mathrm{g}}^{\mathrm{a}} S_{\mathrm{g}}\right)}{\mathrm{D} t}+\left(\theta_{1}^{\mathrm{a}} S_{1}+\theta_{\mathrm{g}}^{\mathrm{a}} S_{\mathrm{g}}\right) \frac{\mathrm{D}_{\mathrm{s}} \phi}{\mathrm{D} t} \\
& \quad+\left[\left(\theta_{1}^{\mathrm{a}} S_{1}+\theta_{\mathrm{g}}^{\mathrm{a}} S_{\mathrm{g}}\right) \phi\right] \nabla \cdot \frac{\mathrm{d} \boldsymbol{u}}{\mathrm{d} t}+\nabla \cdot\left(\boldsymbol{j}_{1}^{\mathrm{a}}+\boldsymbol{j}_{\mathrm{g}}^{\mathrm{a}}\right)=f^{\mathrm{a}}
\end{aligned}
$$

The momentum balance for the whole medium reduces to the equilibrium of stresses if inertial terms are neglected,

$$
\nabla \cdot \sigma+b=0
$$

where $\sigma$ is the stress tensor and $b$ is the vector of body forces.

Finally, the equation for internal energy balance for the whole porous medium is established, taking into account the internal energy in each phase and the energy flux by conduction and by advection of the three phases.

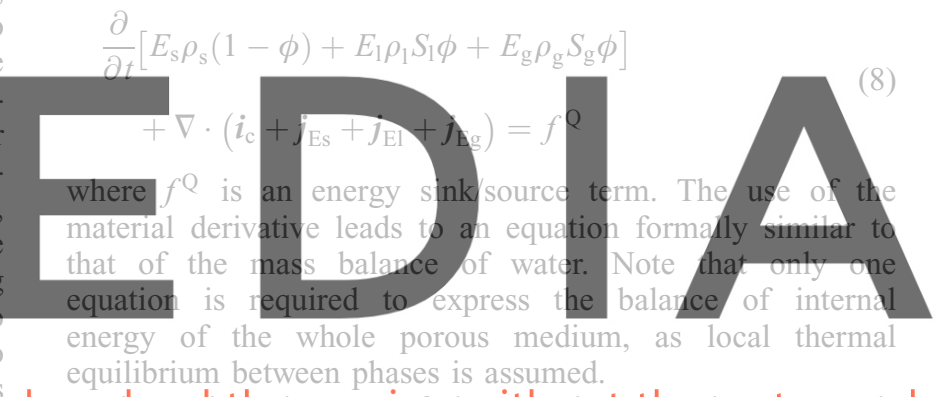
equilibrium between phases is assumed.

ow who adinthenversiofnhwithouts thethatermark ables: solid displacements, $u$ (three spatial directions); liquid pressure $P_{1}$; gas pressure $P_{\mathrm{g}}$; and temperature $T$.

Constitutive equations and equilibrium restrictions

A fundamental part of the formulation is constituted by the set of constitutive laws and equilibrium restrictions. The constitutive equations establish the link between the state variables (or unknowns) and the dependent variables. The governing equations are finally written in terms of the unknowns when the constitutive equations are substituted in the balance equations.

Another series of relationships that relates dependent variables with unknowns are the equilibrium restrictions. They are obtained assuming chemical equilibrium for dissolution of a particular species in a phase. This assumption is appropriate, because those processes are fast compared with the transport phenomena that take place in porous media, and therefore they are not rate controlling. The concentration of vapour in the gas phase and the amount of air dissolved in the liquid phase are governed by expressions of this type.

The constitutive equations and equilibrium restrictions adopted are summarised in Table 1. The following points should be noted:

(a) The balances of momentum for fluid phases and dissolved species are reduced to constitutive laws: Darcy's law and Fick's law. 
Table 1. Summary of constitutive laws and equilibrium restrictions

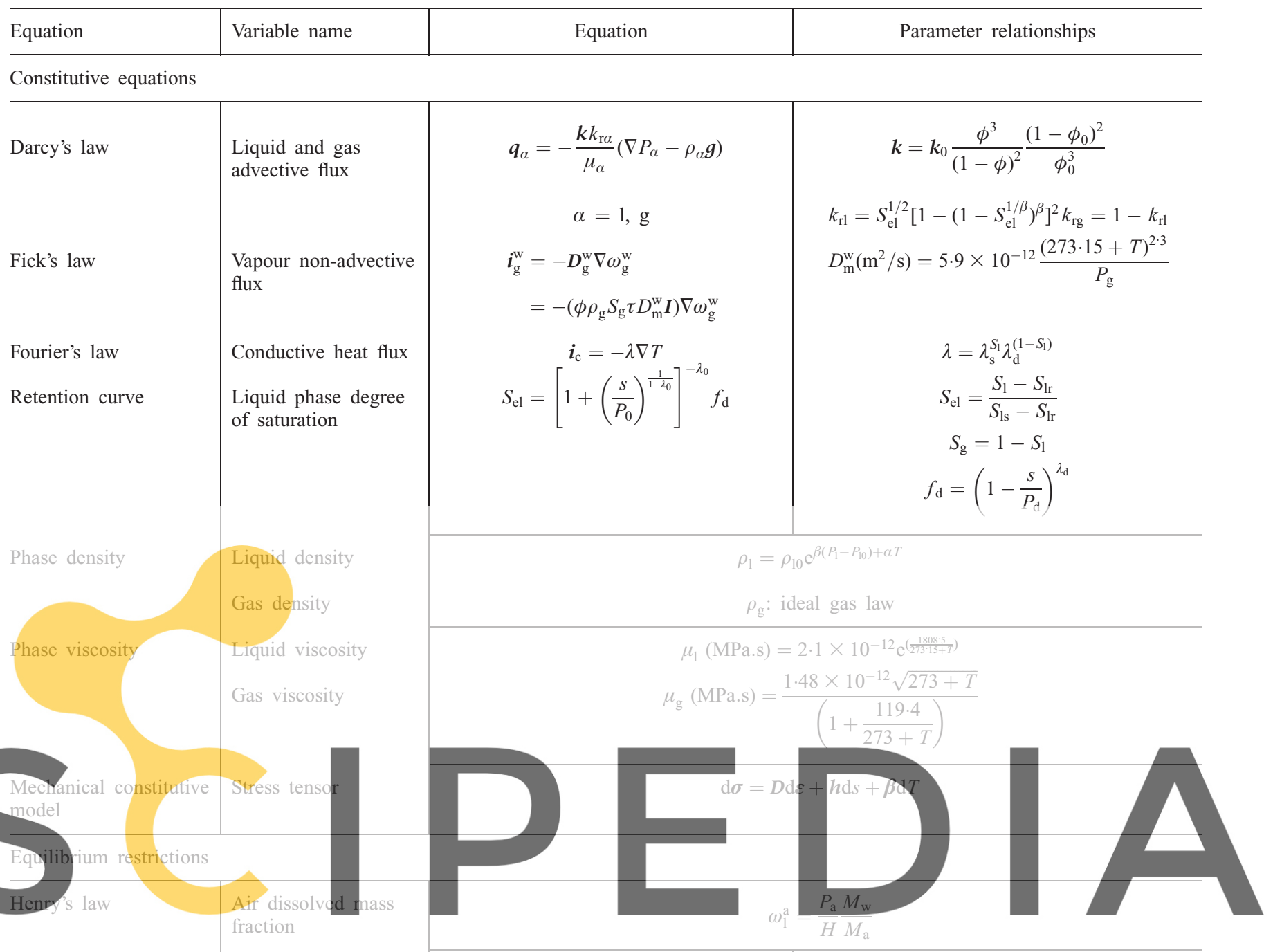

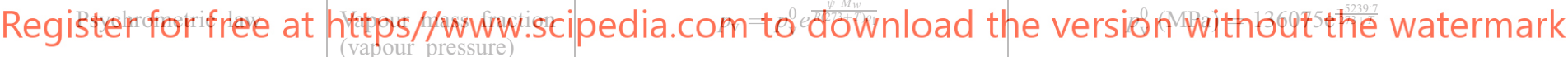

(b) Fourier's law: thermal conductivity depends on the porosity and state of hydration of the material through a geometric mean expression.

(c) Darcy's law: hydraulic conductivity depends on porosity, on degree of saturation and, via water viscosity, on temperature.

(d) Fick's law is adopted for vapour diffusion. A tortuosity coefficient, $\tau$, is included to take into account the effect of a porous medium on the diffusion coefficient.

(e) The mechanical constitutive law explicitly considers the effects of strains, suction and temperature changes.

The formulation outlined above has been discretised in space (finite elements) and time (finite differences) in order that it can be used for numerical analysis. The basic formulation and numerical discretisation constitute the bases of a computer code, CODE_BRIGHT, which has been used to perform the analysis reported below (Olivella et al., 1996).

\section{FEATURES OF THE ANALYSIS AND MATERIAL}

\section{PARAMETERS}

Features of the analysis

The analysis reported in this paper has been called the OBC (operational base case). It corresponds to the analysis performed at the start of the test using the best information on initial and boundary conditions and on material parameters at the time. The results cannot be considered strictly as a Class A prediction because analysis and test overlapped for a few months. The reason for this overlap was that the final heating protocol and the time of switching on the heaters were not decided until quite late in the planning stage. In any case, the results of the analyses are compared with observations over a five-year period, as well as with the measurements made during dismantling. Therefore the analysis results reported herein can be considered, to a large extent, predictions. Other analyses have been performed to elucidate specific aspects of the test, but they are not included here.

The analysis has assumed axisymmetric conditions using the mesh shown in Fig. 11. The outer boundary is placed at a distance of $50 \mathrm{~m}$ from the tunnel axis. The canister, liner, clay backfill, concrete plug and host rock have been represented.

The region of the GTS where the test was performed was intensively studied to obtain the field data required to prescribe the initial and boundary conditions in the rock (Huertas et al., 2006). Based on that information, an initial constant temperature of $12^{\circ} \mathrm{C}$ has been assumed throughout. Liquid pressure on the mesh outer boundaries is based on the recorded and back-calculated values obtained during the 


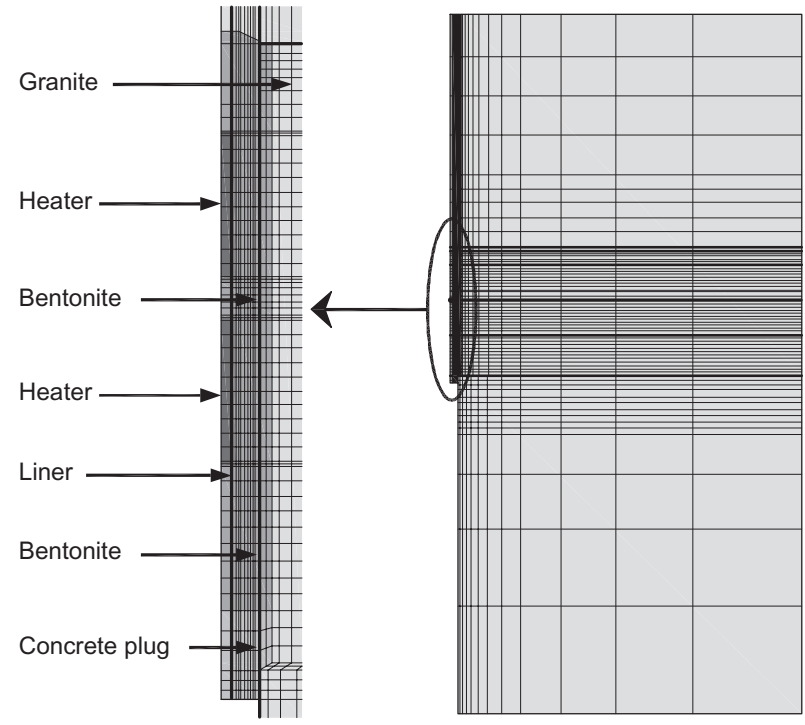

Fig. 11. Axisymmetric mesh for analysis of in situ heating test

hydrogeological study of the test area. The initial stress field was assumed uniform and isotropic with a stress value of $28 \mathrm{MPa}$, the measured mean in situ stress in the zone. Initial granite porosity was taken as $0 \cdot 01$.

The analysis started simulating the tunnel excavation followed by the construction of the bentonite barrier and the insertion of the heater. In accordance with the measurements performed during installation, an initial water content of

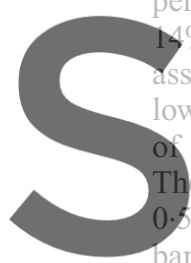
and an average dry densi sumed for the clay barrier. ower than that used for block some very limited drying dur
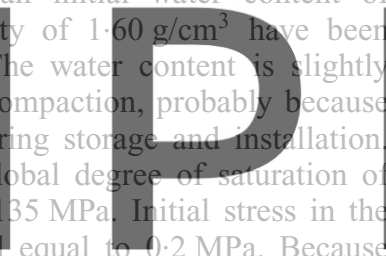
and a value of suction

arrier is assumed isotropic and equal to $0.2 \mathrm{MPa}$. Because
he experiment was not gas tight, a constant gas pressure

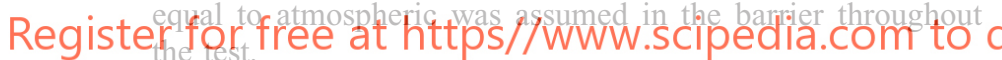

After installation of heaters and clay barrier, an isothermal period of four months was simulated, during which a very limited amount of bentonite hydration occurred. Afterwards, power was applied to the heaters in accordance with the actual test protocol (Fig. 9). Once the temperature value of $100^{\circ} \mathrm{C}$ was reached, the simulation was switched to temperature control. The instant of switching the heaters on is taken as time zero, and the simulation was run up to five years, the duration of the heating stage. Although there was a gap between the bentonite and the rock in the upper part of the barrier, and a smaller one between the barrier and the liner, the analysis has assumed that, initially, there was contact in those interfaces.

\section{Material parameters: bentonite}

The thermal conductivity of the bentonite is given by

$$
\lambda=\lambda_{\mathrm{sat}}^{S_{1}} \lambda_{d r y}^{\left(1-S_{1}\right)}
$$

where the values of $\lambda_{\text {sat }}=1.15$ and $\lambda_{\text {dry }}=0.47 \mathrm{~W} / \mathrm{m}^{\circ} \mathrm{C}$ have been determined based on the experimental measurements presented in Fig. 12. Note that equation (9) expresses the dependence of thermal conductivity on water content and porosity through the degree of saturation parameter. The specific energy of the solid phase of the bentonite is $E_{\mathrm{s}} / T=$ $1091 \mathrm{~J} / \mathrm{kg}^{\circ} \mathrm{C}$ ).

Hydraulic conductivity is directly related to intrinsic per-

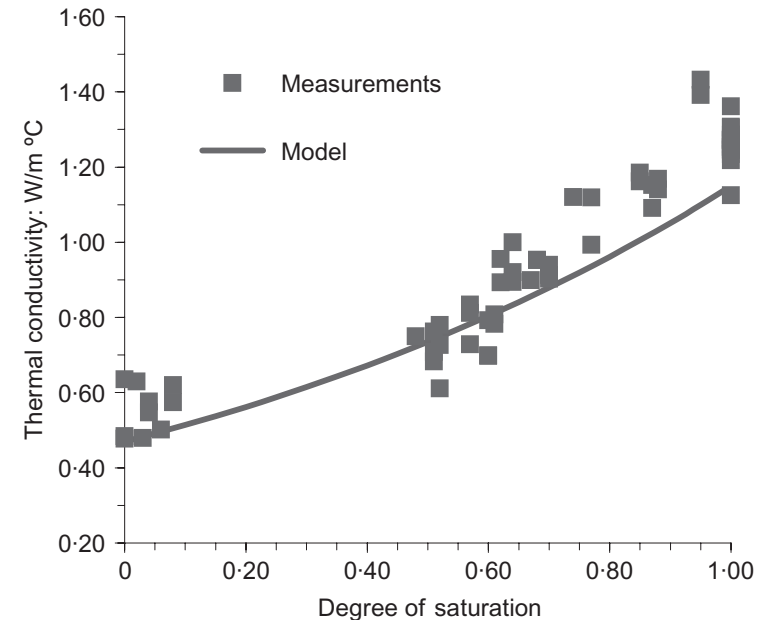

Fig. 12. Variation of bentonite thermal conductivity with degree of saturation: experimental results (Villar, 2002) and adopted relationship

meability, which in turn is assumed to depend on porosity according to

$$
\boldsymbol{k}=k_{0} \frac{\phi^{3}}{(1-\phi)^{2}} \frac{\left(1-\phi_{0}\right)^{2}}{\phi_{0}^{3}} \boldsymbol{I}
$$

where $k_{0}$ is the reference permeability at the reference porosity $\phi_{0}$.

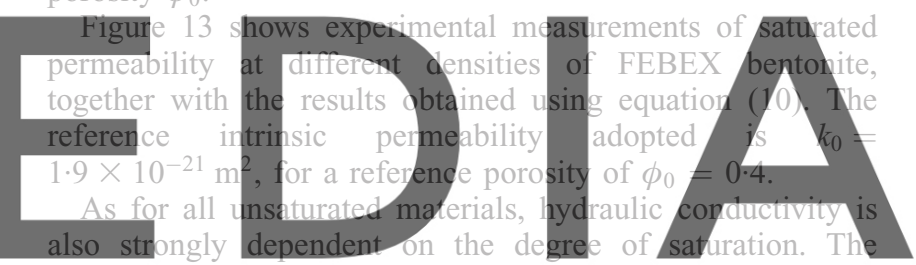

relative permeability of the liquid phase $\left(k_{\mathrm{rl}}\right)$ is given by

\section{download the version without the watermark}

where $n$ is a model parameter and $\mathrm{S}_{\mathrm{el}}$ is the effective degree of saturation, evaluated as

$S_{\mathrm{el}}=\frac{S_{1}-S_{\mathrm{lr}}}{S_{\mathrm{ls}}-S_{\mathrm{lr}}}$

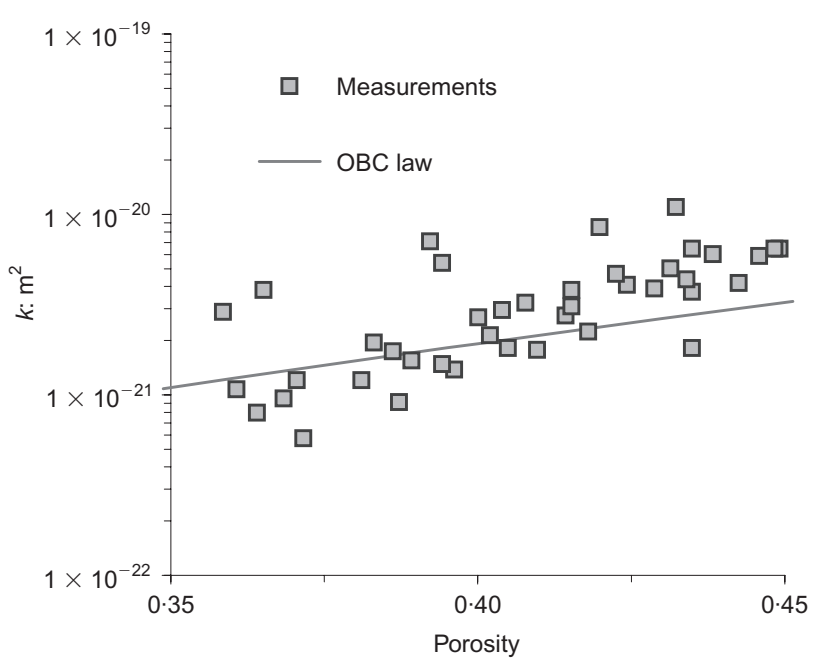

Fig. 13. Variation of bentonite intrinsic permeability with porosity: experimental results (Villar, 2002) and adopted relationship 
where $S_{\mathrm{lr}}$ is the residual saturation and $S_{\mathrm{ls}}$ is the maximum saturation.

The variation of relative permeability is difficult to determine directly, and it is necessary to resort to indirect means of estimation. During the pre-operational laboratory study, the parameters of the relative permeability law for the bentonite were determined from back-calculation of a hydration test carried out in a small cell (Pintado et al., 2002), yielding the following parameters: $S_{\mathrm{lr}}=0.01, S_{\mathrm{ls}}=1 \cdot 0$ and $n=3$. For the vapour diffusion law (Fick's law), a tortuosity $\tau=0.8$ has been adopted (Pintado et al., 2002).

The retention curve adopted in the analysis is a modification of the expression proposed by van Genuchten (1978),

$$
S_{\mathrm{el}}=\left[1+\left(\frac{s}{P_{0}}\right)^{\frac{1}{1-\lambda_{0}}}\right]^{-\lambda_{0}} f_{\mathrm{d}}
$$

where $P_{0}$ and $\lambda_{0}$ are model parameters, and $f_{\mathrm{d}}$ is a function included in order to model the high-suction range properly, and given by:

$$
f_{\mathrm{d}}=\left(1-\frac{s}{P_{\mathrm{d}}}\right)^{\lambda_{\mathrm{d}}}
$$

where $P_{\mathrm{d}}$ and $\lambda_{\mathrm{d}}$ are model parameters. When $\lambda_{\mathrm{d}}=0$ the original model is recovered.

The parameters for the retention curve (Table 2) were based on tests under constant-volume conditions that are closer to the confined condition of the bentonite in the test (Fig. 14). Experimental results (Villar and Lloret, 2004) have also shown that the influence of tomperature on the retoution curve is quite small, and therefore the analysis. To represent the mechanical be modified form of the Barcelona 1990), has been employed
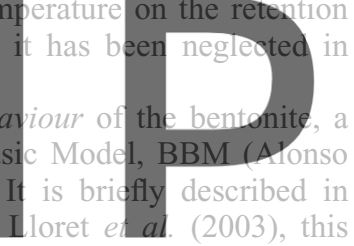

Register for free at. https/fwww scipedia.comm to

\begin{tabular}{l|c|c|c|c}
\hline Model & $P_{0}: \mathrm{MPa}$ & $\lambda_{0}$ & $\lambda_{\mathrm{d}}$ & $P_{\mathrm{d}}: \mathrm{MPa}$ \\
\hline In situ & 7 & $0 \cdot 10$ & $2 \cdot 10$ & 1100 \\
\hline
\end{tabular}

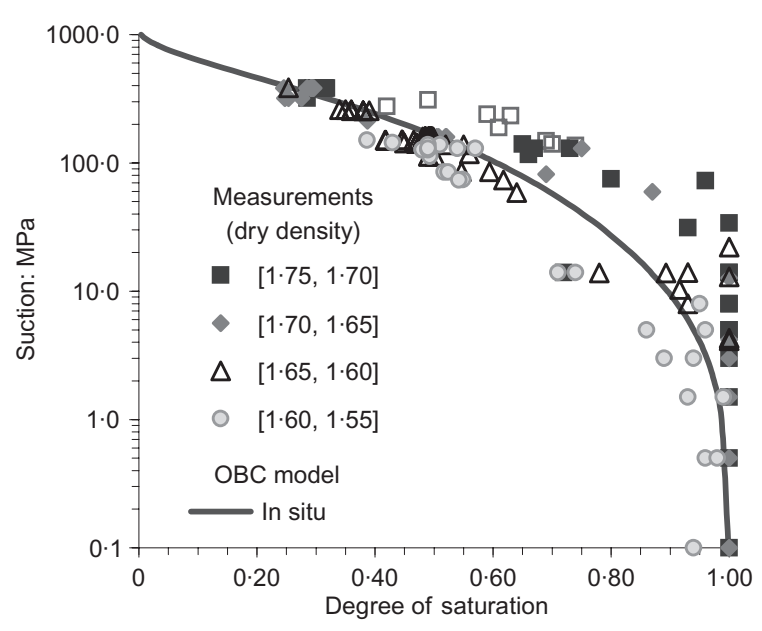

Fig. 14. Retention curve adopted in numerical analysis (full line), together with experimental data for FEBEX bentonite (symbols) particular form of the model is quite suitable for reproducing the behaviour of compacted unsaturated swelling clays. The parameters of the mechanical model (Table 3) have been determined mainly from the back-calculation of constant-volume swelling pressure tests performed during the pre-operational stage of the in situ experiment (Villar, 2002). Again, these tests are the ones more closely resembling the confined state of the bentonite in the field. The thermomechanical response of the bentonite is simply accounted for by a coefficient of linear expansion, $\alpha_{0}$. Fig. 15 shows experimental data for the thermal expansion of the bentonite, from which the adopted value of $\alpha_{0}=1.5 \times 10^{-4}{ }^{\circ} \mathrm{C}^{-1}$ has been derived.

\section{Material parameters: granite}

Much simpler constitutive relations have been required to define the THM behaviour of the granite. They are based on the results of experimental investigations on Grimsel granite reported in Keusen et al. (1989) and Frieg \& Vomvoris (1994). Thermal conductivity has been determined to be $3.6 \mathrm{~W} / \mathrm{m}^{\circ} \mathrm{C}$ and the specific energy of the solid phase $E_{\mathrm{S}} / T=793 \mathrm{~J} / \mathrm{kg}^{\circ} \mathrm{C}$. The average intrinsic permeability of the granite is $8 \times 10^{-18} \mathrm{~m}^{2}$, which corresponds approximately to a hydraulic permeability of $8 \times 10^{-11} \mathrm{~m} / \mathrm{s}$ at $20^{\circ} \mathrm{C}$ (Ortuño et al., 2005). No variation with porosity is considered. As would be expected in a rock mass, there are significant variations of permeability in different zones of the rock, depending on the degree of fracturing and on the presence of contacts with the lamprophyre dykes; the value
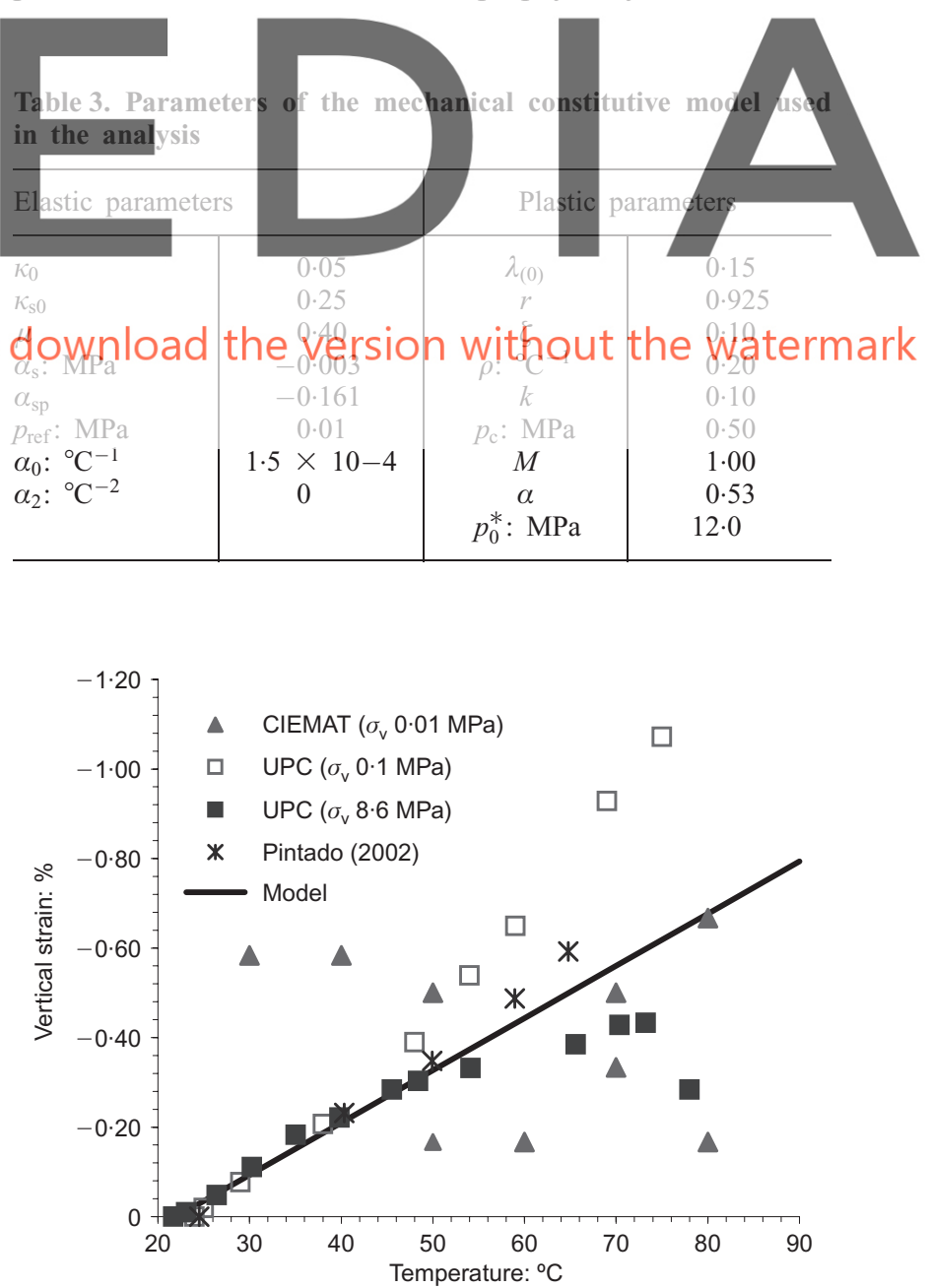

Fig. 15. Variation of thermally induced vertical strain with temperature (Romero et al., 2005) 
quoted is a mean one for the test section. However, it has turned out that these local variations did not affect the performance of the test, because the low permeability of the bentonite controlled the rate of water ingress; effectively, all parts of the granite supplied sufficient amounts of water along the whole test area. Because there was no evidence of desaturation of the rock, the granite is assumed saturated throughout.

The thermomechanical behaviour of the granite is characterised by a linear elastic model $\left(K=2.92 \times 10^{4} \mathrm{MPa}, G_{\mathrm{t}}\right.$ $=1.35 \times 10^{4} \mathrm{MPa}$ ) and a coefficient of linear expansion, $\left.\alpha_{0}=7.8 \times 10^{-6}{ }^{\circ} \mathrm{C}^{-1}\right)$.
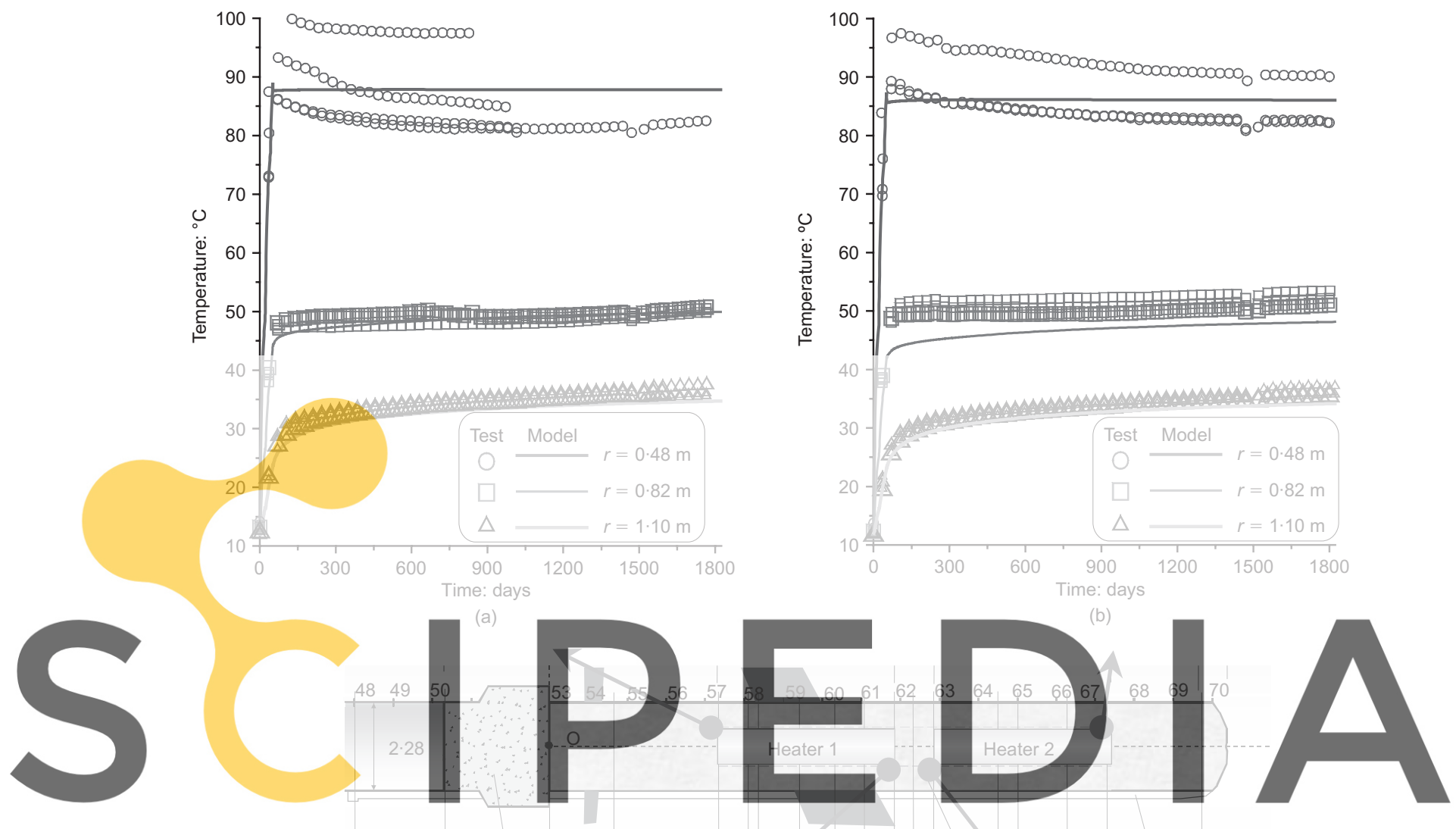

Register for free at https//wwwonstipedia.com to download theeversion wiffsblout the watermark

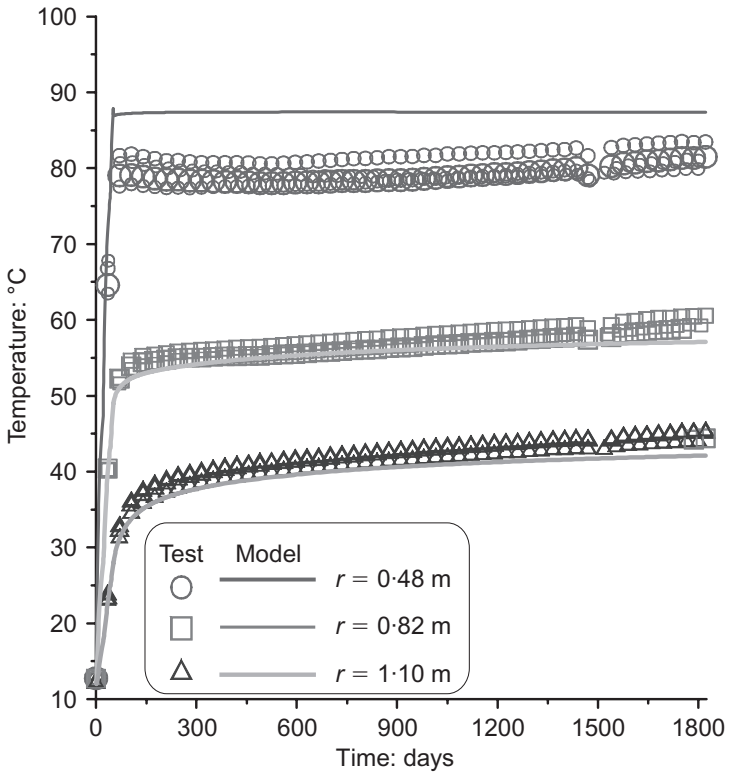

(c)

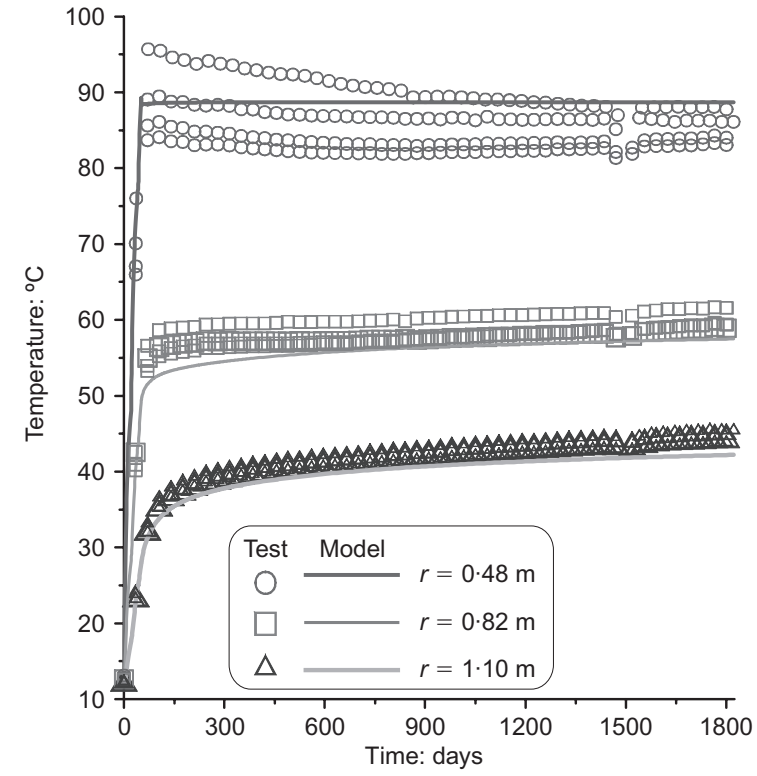

(d)

Fig. 16. Evolution of temperatures in bentonite barrier, observations and computed results: (a) section D1, $x=4 \cdot 42 \mathrm{~m}$; (b) section D2, $x=14.38 \mathrm{~m}$; (c) section G, $x=8.91 \mathrm{~m}$; (d) section I, $x=9.93 \mathrm{~m}$ 
TEST OBSERVATIONS AND INTERPRETATION:

ENGINEERED BARRIER

In this section, representative test observations of the test concerning the bentonite barrier are presented. Test observations are plotted alongside the predictions of the numerical analysis to assist in the interpretation, and to assess both the reliability of the test results and the performance of the model. All observations extend to the five-year duration of the heating stage (1827 days).

\section{Thermal}

Figure 16 shows the evolution of the temperature in various sections of the test. In each section, temperatures at different radial distances from the axis of the tunnel are plotted. More than one set of observations for a particular radial distance and section are shown, because temperature sensors were sometimes placed along several radial lines. The repeatability of results indicates the degree of approximation to thermal axisymmetric conditions and, indirectly, the reliability of the observations.

It can be noted that, after the initial stage, temperatures generally rise very slowly throughout the barrier. The analysis reproduces the observations quite well, although this is helped by the fact that it is a temperature-controlled test. Because practically all the energy is transported by conduction, the good agreement at different radial distances indicates that the value of thermal conductivity is well captured, even when the barrier is subjected to changes in water content and degree of saturation.

\section{Hydraulic}

Of more interest, and more challenging, are the observations and predictions of the hydraulic changes inside the barrier. Fig. 17 shows the variation with time of relative humidity, measured with capacitive sensors, in two sections: a cool one away from the heater $(\mathrm{C})$ and a hot one between the two heaters $(\mathrm{H})$. Relative humidity is plotted because it is the actual parameter measured by the capacitive transducers. Total suction $\psi$ is related to relative humidity $\mathrm{RH}$ via the psychrometric (Kelvin's) equation,

$$
\mathrm{RH}=\exp \left[\frac{\psi M_{\mathrm{w}}}{R(273+T) \rho_{1}}\right]
$$

where $M_{\mathrm{w}}$ is the molecular weight of water.

It can be observed that in the cool section $\mathrm{C}$ there is a monotonic increase of relative humidity corresponding to the progress of hydration caused by water drawn from the host rock. The inner region, however, is far from being saturated after five years. The hydraulic behaviour is more complex in the hot section close to the heaters. In the zone near the rock, and in the middle of the barrier, there is a monotonic increase of relative humidity, reflecting again the process of hydration induced by the rock water. However, in the region closer to the tunnel axis it can be observed that there is first an increase of relative humidity followed immediately by drying; finally, a gentle increase of relative humidity occurs. Assisted by the examination of the numerical analysis results, it is possible to identify the processes underlying this behaviour. The first relative humidity increase is due to a

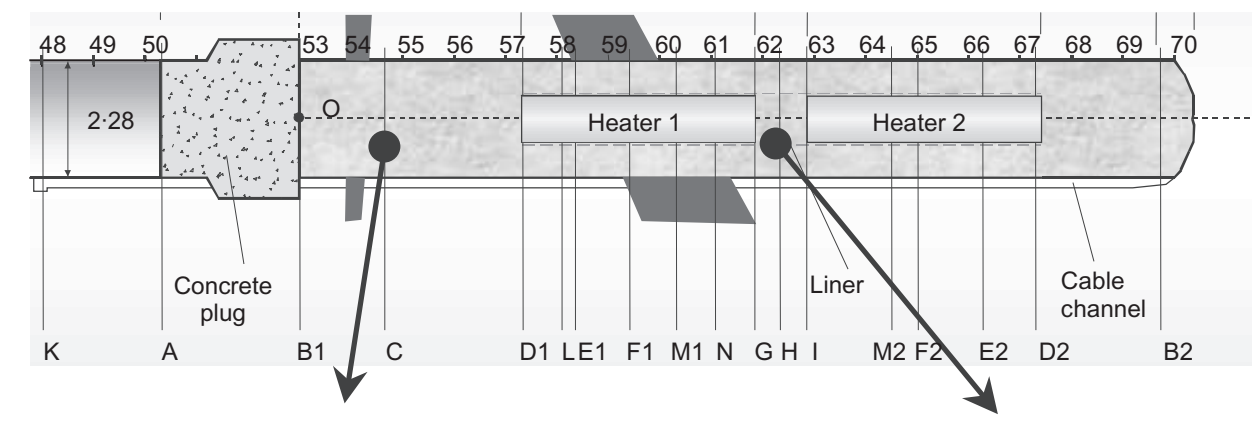

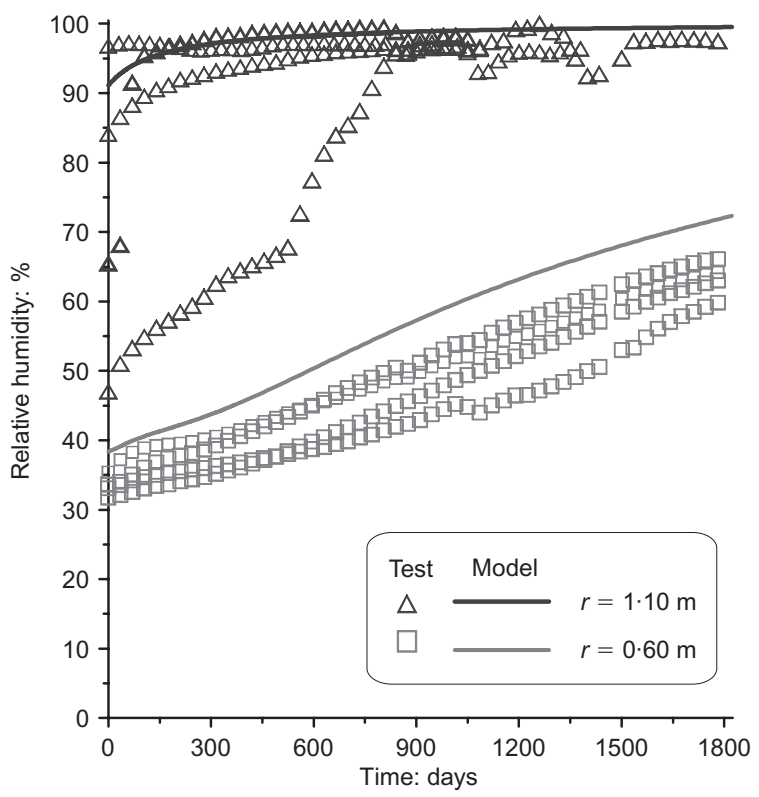

(a)

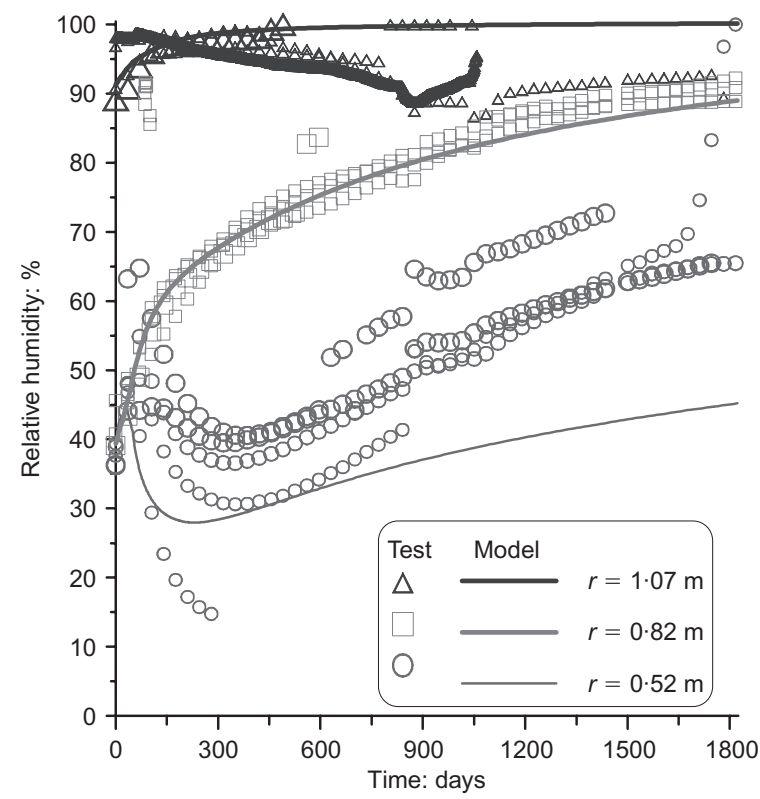

(b)

Fig. 17. Evolution of relative humidity in bentonite barrier, observations and computed results: (a) sections $\mathrm{C}$ (cool), $x=$ $1.80 \mathrm{~m}$; (b) section $H$ (hot), $x=9.50 \mathrm{~m}$ 
vapour front (driven by heating) passing through the observation point. After that, a temperature increase causes evaporation and, therefore, drying of the material. After approximately one year general hydration takes over, causing the final gradual increase of relative humidity. Vapour movement plays an important role in the evolution of the hydraulic state of the barrier in the hot zone; indeed, a significant part of the early hydration of the middle and outer barrier

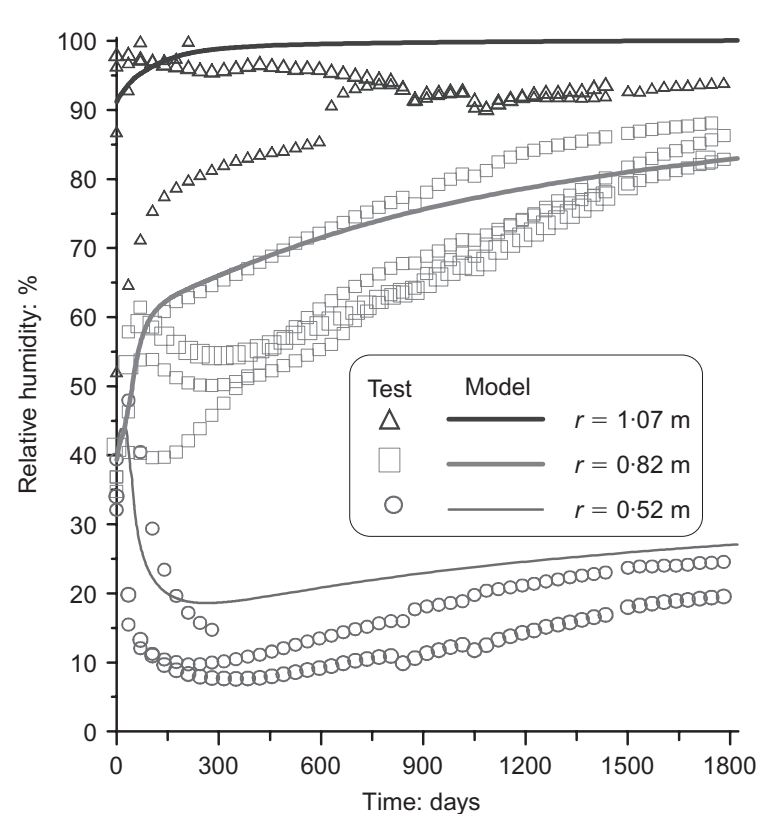

(a)

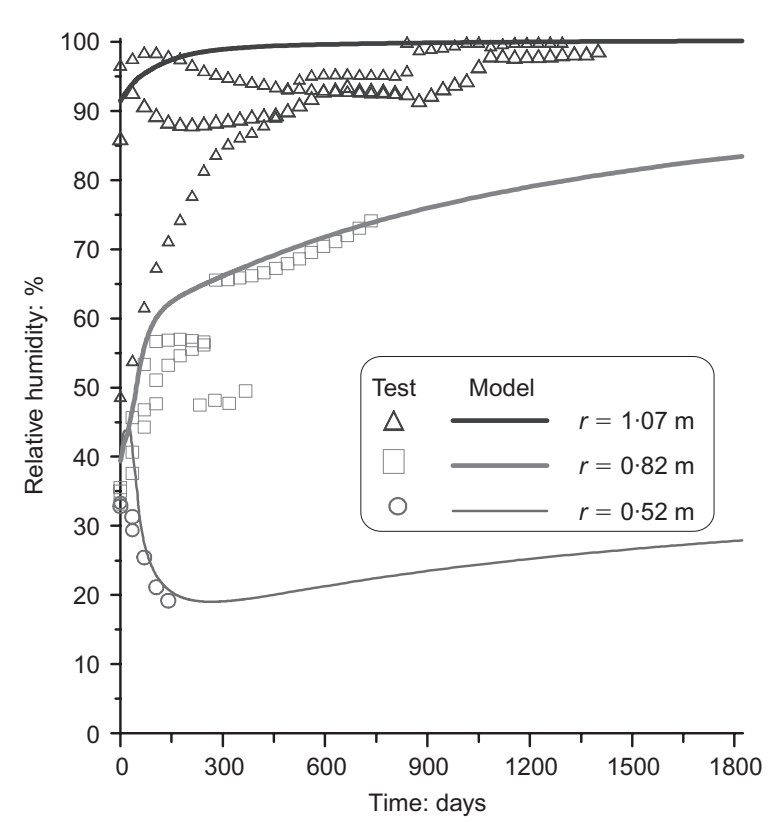

(b)

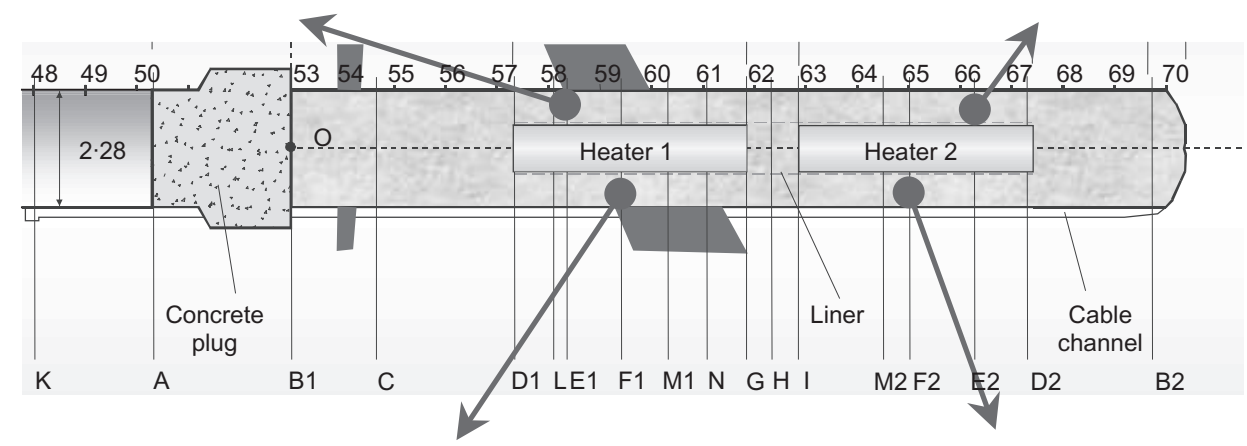

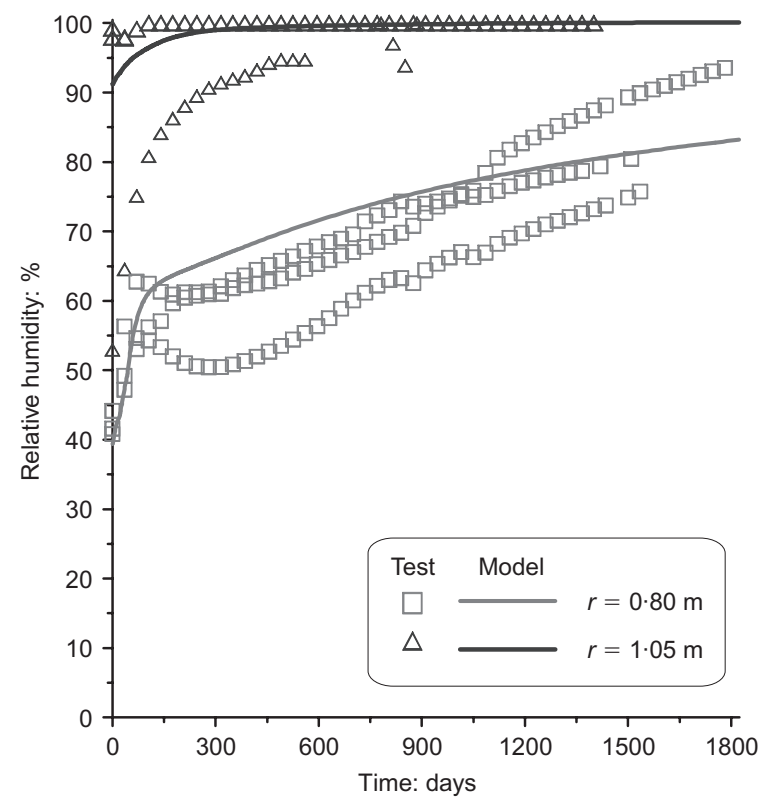

(c)

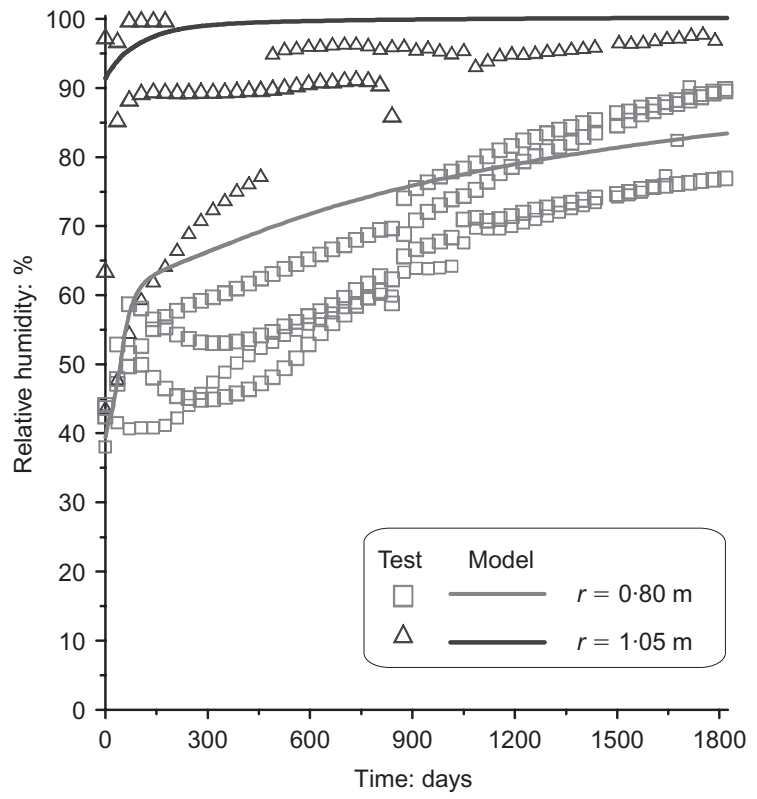

(d)

Fig. 18. Evolution of relative humidity in bentonite barrier, observations and computed results: (a) section E1, $x=$ $5.53 \mathrm{~m}$; (b) section E2, $x=13.44 \mathrm{~m}$; (c) section F1, $x=6.69 \mathrm{~m}$; (d) section F2, $x=12.30 \mathrm{~m}$ 
zones is due to the condensation of vapour coming from the inner region. Naturally, these hydraulic changes cause variations in thermal conductivity that, in turn, affect heat conduction. The analysis is able to reproduce the thermohydraulic observations very satisfactorily: even from a quantitative point of view, predictions agree quite well with observations.

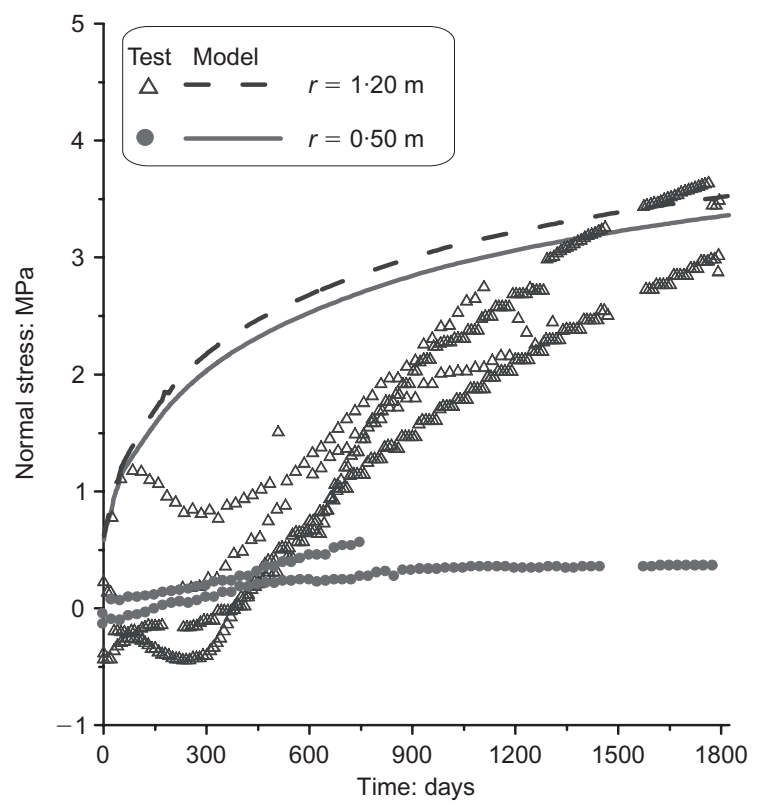

(a)
Figure 18 shows more results for the variation of relative humidity with time in four additional hot sections facing the heaters. The observed behaviour is similar to that described above for section H. Again, the predictions from the numerical model are quite satisfactory. In all cases the clay barrier is very far from full saturation at the end of the five years of heating.

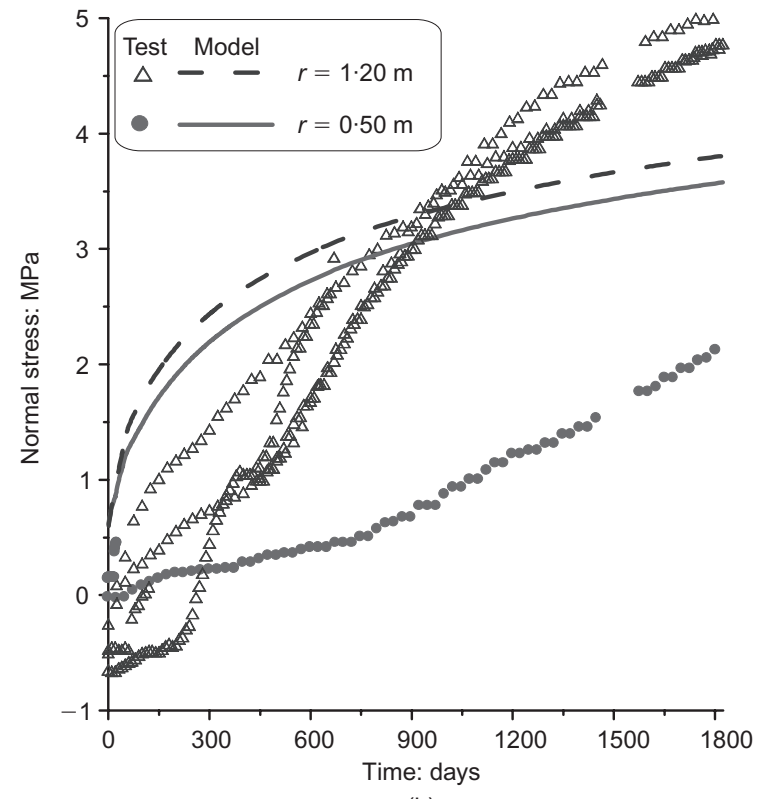

(b)

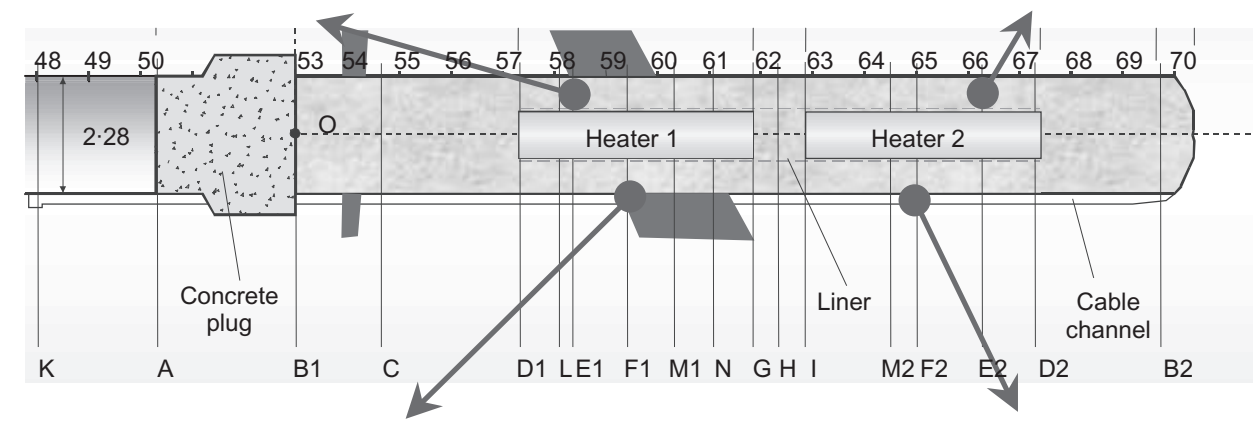

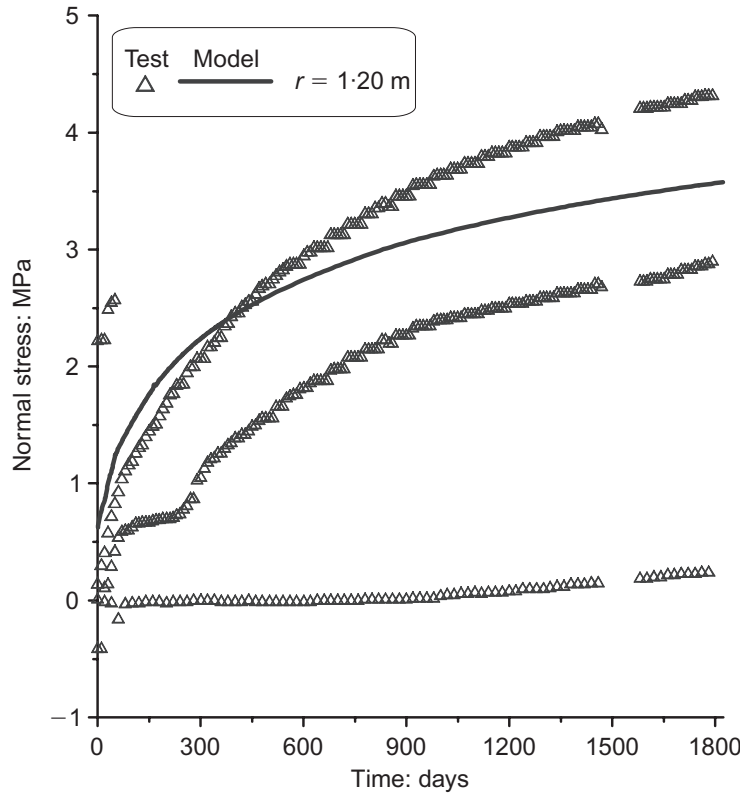

(c)

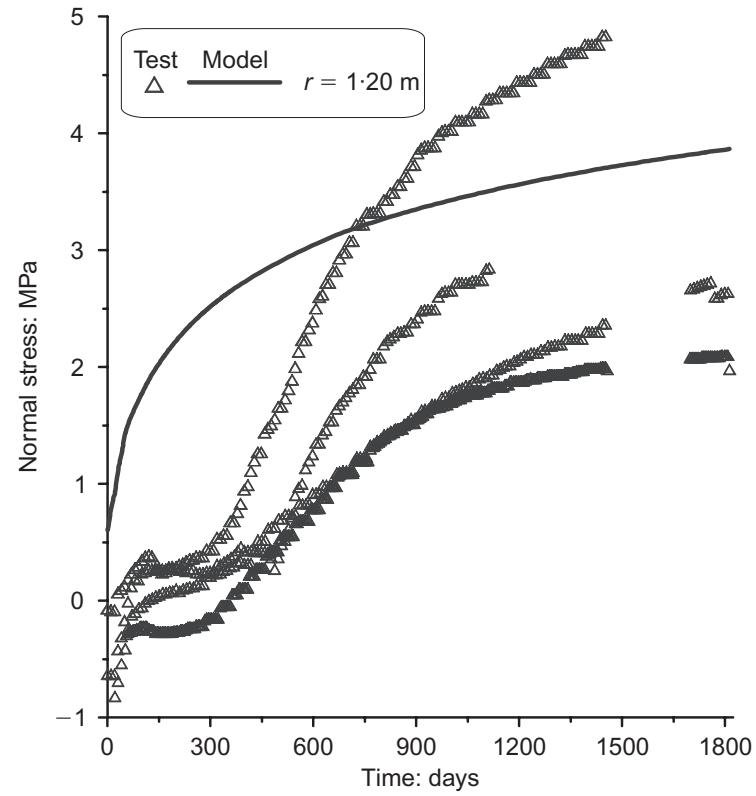

(d)

Fig. 19. Evolution of total stresses in bentonite barrier, observations and computed results: (a) section E1, $x=5 \cdot 52 \mathrm{~m}$; (b) section E2, $x=13.45 \mathrm{~m}$; (c) section F1, $x=6.80 \mathrm{~m}$; (d) section F2, $x=12.20 \mathrm{~m}$ 


\section{Mechanical}

Because of the very limited movements that the confined bentonite barrier can undergo, the main mechanical parameter considered is total stress. It would be expected that stresses in the barrier will increase very significantly during hydration because of the high swelling potential of a heavily compacted bentonite. As Fig. 19 demonstrates, such an increase is indeed observed, reaching quite high values of

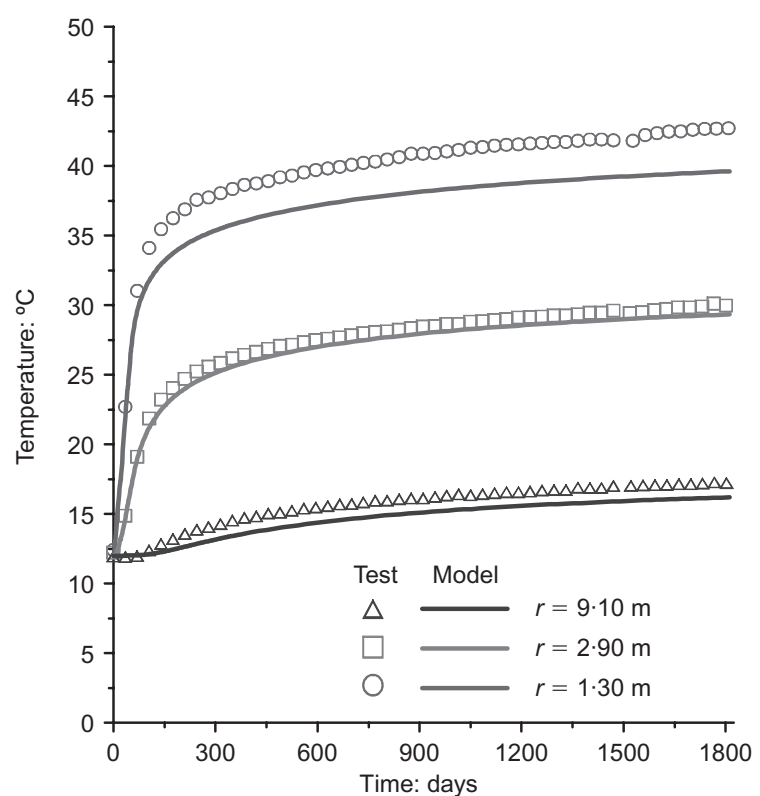

(a)

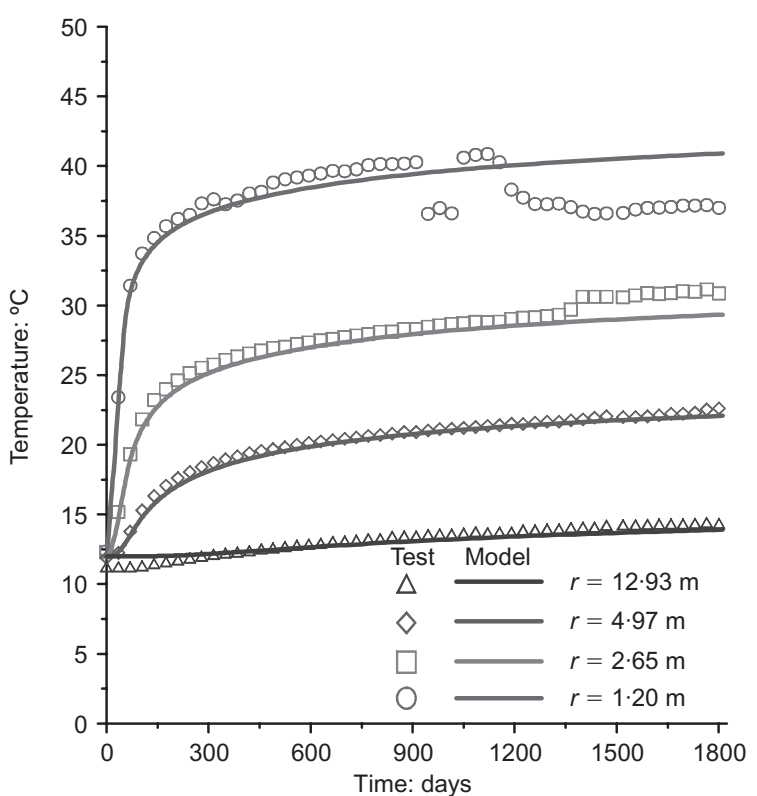

(b)

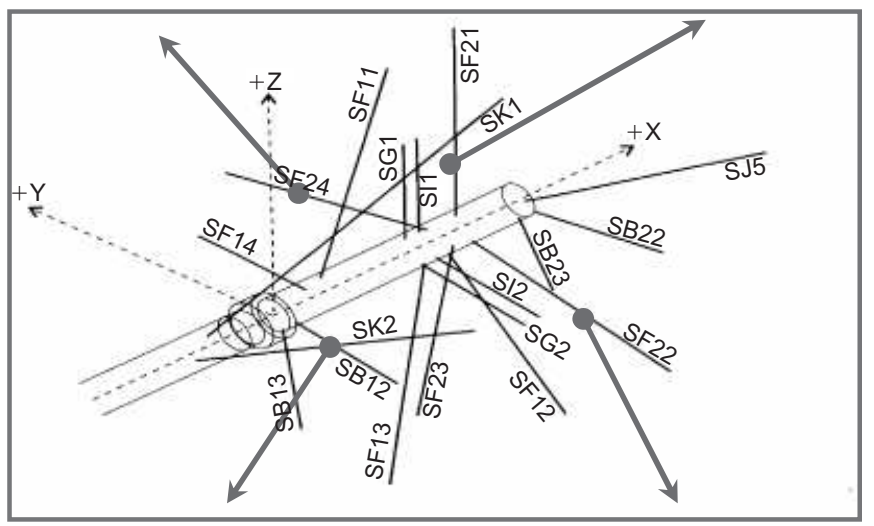

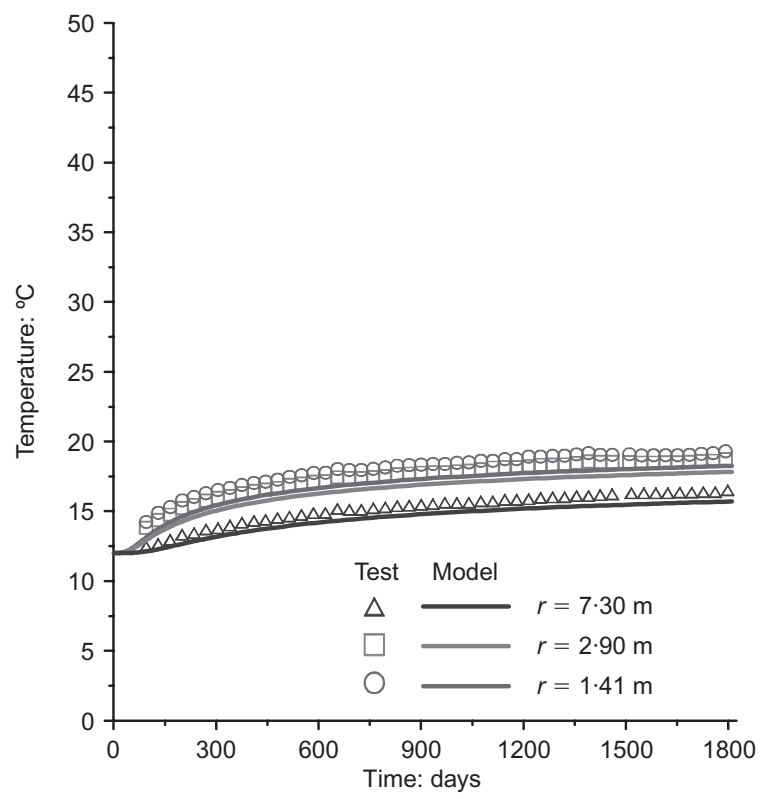

(c)

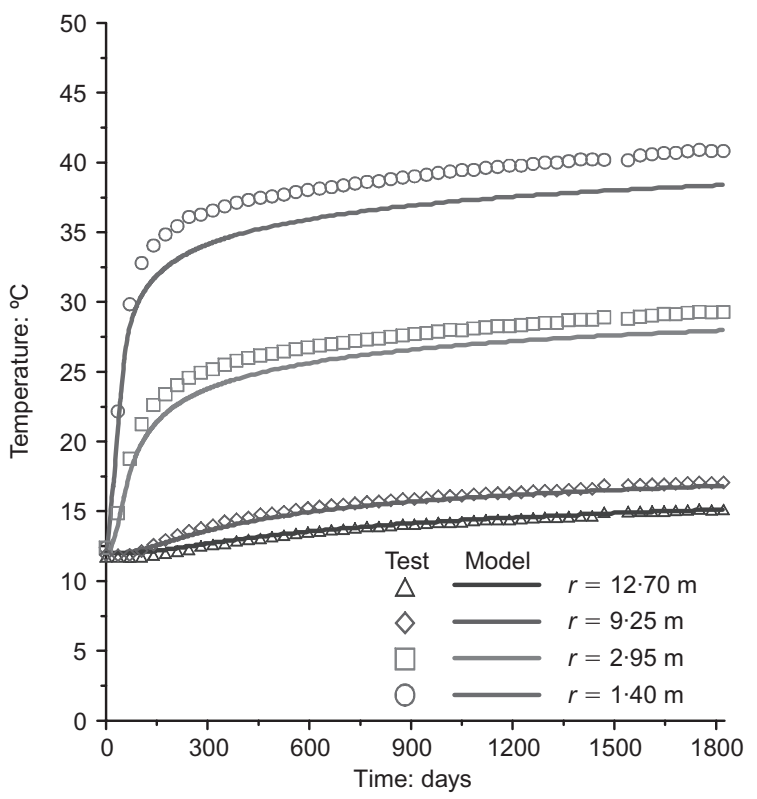

(d)

Fig. 20. Evolution of temperatures in granite, observations and computed results: (a) section borehole SF24; (b) SF21; (c) SB12; (d) borehole SF22 
total stresses at the end of the test, of the order of 2-4 MPa. Unfortunately, it is not easy to measure total stresses reliably, as the scatter of observations clearly indicates. It is therefore difficult to check the agreement with the results from the analysis in detail. However, it is possible that the slower development of the measured swelling stresses, as compared with the predictions from the analysis, may be due, at least in part, to the initial liner/barrier and rock/ barrier gaps, not accounted for in the modelling. In any case, the predicted final total stress in the barrier is similar to that measured in quite a number of total stress cells.

\section{TEST OBSERVATIONS AND INTERPRETATION: GRANITE}

The host rock, granite, is subjected to more limited heat loading, and therefore the observed effects are bound to be more muted. However, to get a complete picture of nearfield behaviour, it is convenient to examine the behaviour of the rock mass during the test.

\section{Thermal}

Figure 20 shows the evolution of the temperature measured in several boreholes. Three temperature sensors at different distances from the tunnel axis were installed in each borehole. Boreholes SF21, SF22 and SF24 are in the zone affected by the heaters, whereas borehole SB12 is close to the test area entrance, where the temperature increase is quite small. In the hot zone, a rapid increase of temperature is again observed at the start of the test, followed by a constant but gentle rise. Observed temperatures in the rock reached a maximum value of about $40^{\circ} \mathrm{C}$. The values and evolution of the temperatures are predicted well in practically all observation points, indicating again that the thermal conductivity estimate was quite accurate.

\section{Hydraulic}

The initial pore pressure field in the granite was determined in a comprehensive hydrogeological investigation performed before the test, which provided the initial hydraulic conditions for the analysis (Ortuño et al., 2005). These pore pressures were subsequently affected by the excavation of the FEBEX tunnel. By modelling this excavation, the new pore pressure distribution was largely reproduced. During the thermal test it was observed that the pore pressures in the granitic rock were little affected by heating. What Fig. 21 shows is basically the recovery of pore pressures after excavation. The same process is in fact predicted by the numerical analysis. This is quite different from the very strong hydrothermal response of argillaceous rocks in similar circumstances (Gens et al., 2007).

\section{Mechanical}

Both displacements and total stresses have been measured in the rock. The measured radial displacements are shown in

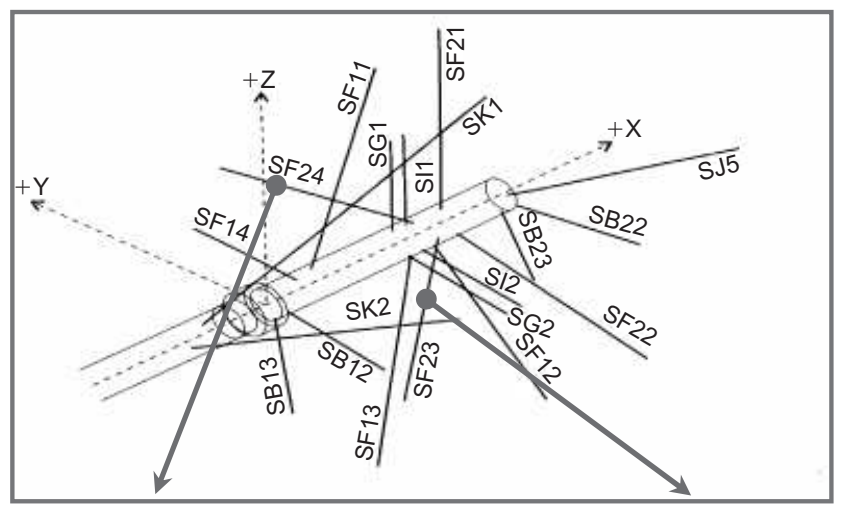

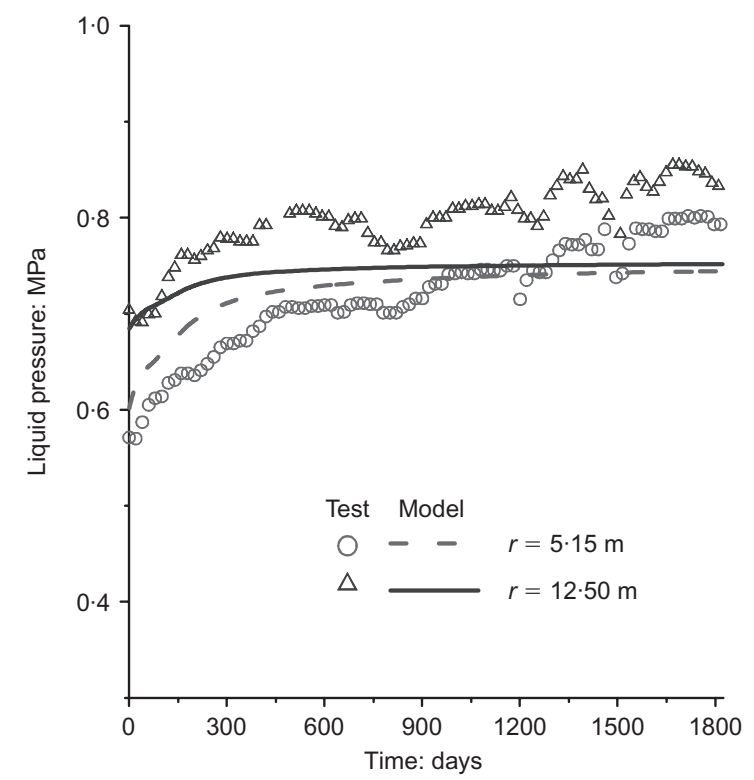

(a)

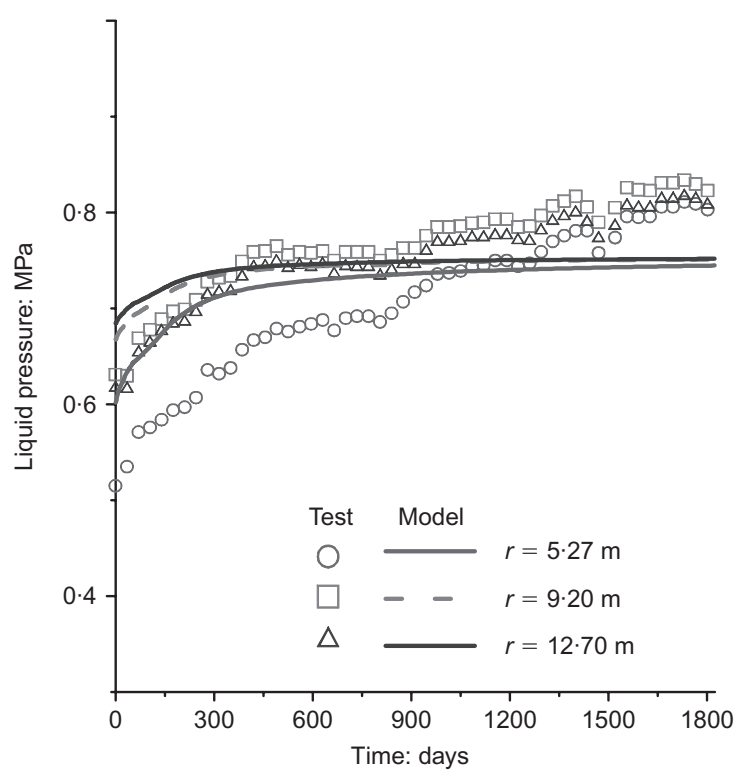

(b)

Fig. 21. Evolution of pore pressures in granite, observations and computed results: (a) section borehole SF24; (b) SF23 
Fig. 22: they are quite small (of the order of $0.1 \mathrm{~mm}$ ), and they develop in response to the increase of temperature. The predicted radial displacements are also small, but larger than the observed ones. It is therefore likely that the thermal expansion of the rock was overestimated in laboratory tests.

Measured normal stresses in borehole SG2 at two different distances from the tunnel axis $(2.95 \mathrm{~m}$ and $7.6 \mathrm{~m})$ are plotted in Fig. 23. Again, the difficulty of measuring stresses is reflected in the rather erratic nature of the observations. It is clear, though, that the magnitude of the stress increase reduces as the distance to the tunnel becomes larger. Although the development of swelling pressure in the bentonite contributes to the rock stress increase, the major factor in rock stress development is the rise of temperature. Stresses computed in the numerical analysis appear to provide a good estimate of the magnitude of the observed stress increase, although it is difficult to judge the accuracy of the predicted evolution.

\section{TEST DISMANTLING}

Exactly after five years of heating, Heater 1 (the one closest to the concrete plug) was switched off. After allowing 33 days for cooling, the bentonite was carefully removed up to the end section of Heater 1, leaving the rest of the barrier in place. At the same time, Heater 1 was removed from the experiment. Those operations lasted for an addi- tional 75-day period. Subsequently, a new shotcrete plug was constructed, and the test on the remaining part of the experiment continued (Fig. 24). Various sections were earmarked for sampling (Fig. 25). A detailed description of the procedures during dismantling is presented in Bárcena et al. (2003).

This partial test dismantling allowed the direct and detailed observation of the state of the barrier after five years of heating and hydration (Fig. 26). In addition, large amounts of quantitative data could be obtained: this information is very valuable for providing an independent check on the performance of the numerical model, as well as on the reliability of the predictions. At selected sections, a large number of specimens were cored out from the barrier (Fig. 27), and dry density and water content were determined immediately in a field laboratory in order to minimise disturbance and humidity loss. This comprehensive set of values of dry density and water content helped to provide a complete picture of the state of the bentonite barrier. Block samples were also taken for laboratory testing, but those results are outside the scope of this paper (Villar et al., 2005). Thanks to the high density of determinations, contours of dry density and water content can be plotted in the sampled sections. An example is presented in Fig. 28, where it can be seen that the process of hydration and associated density changes is basically axisymmetric, supporting the assumption made in the numerical analysis.

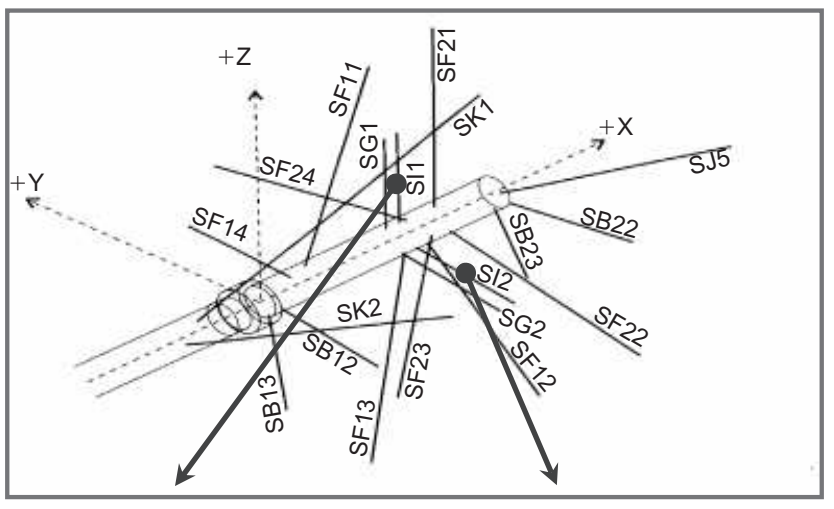

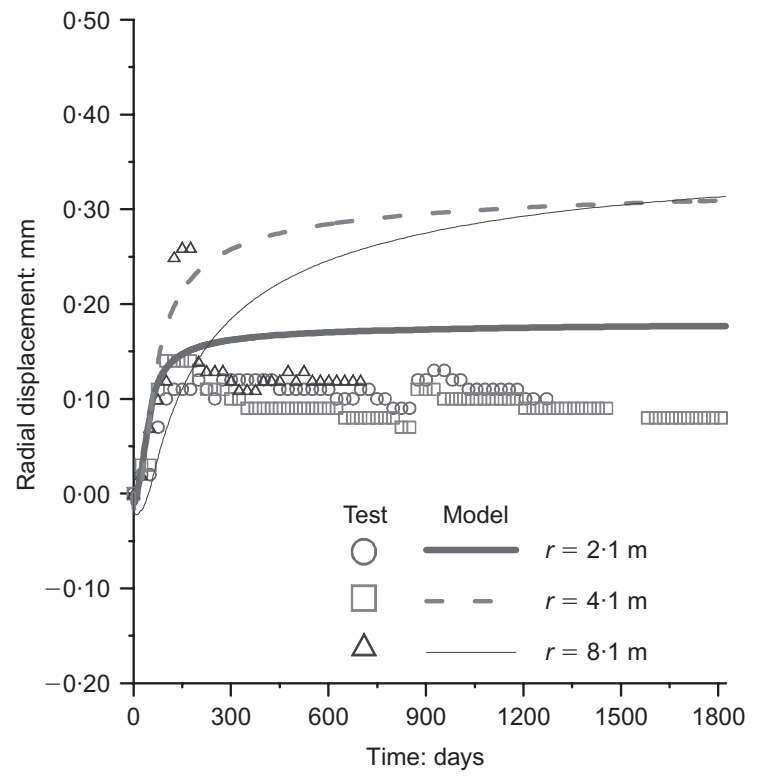

(a)

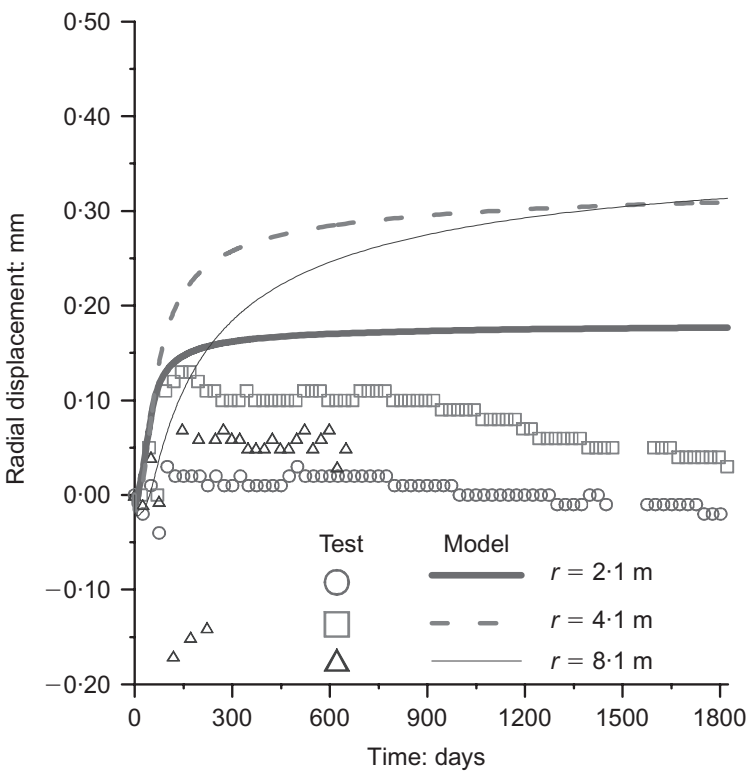

(b)

Fig. 22. Evolution of radial displacements in granite, observations and computed results: (a) section borehole SI1, $x=10 \cdot 16 \mathrm{~m}$; (b) SI2, $x=10 \cdot 20 \mathrm{~m}$ 


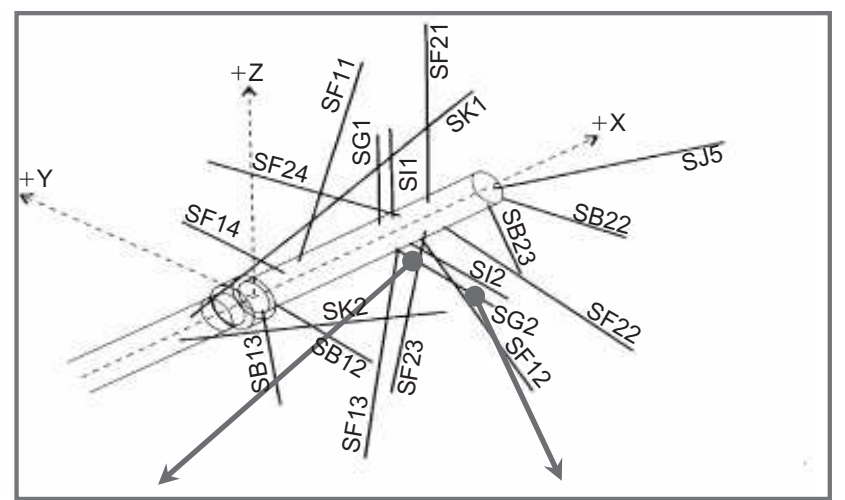

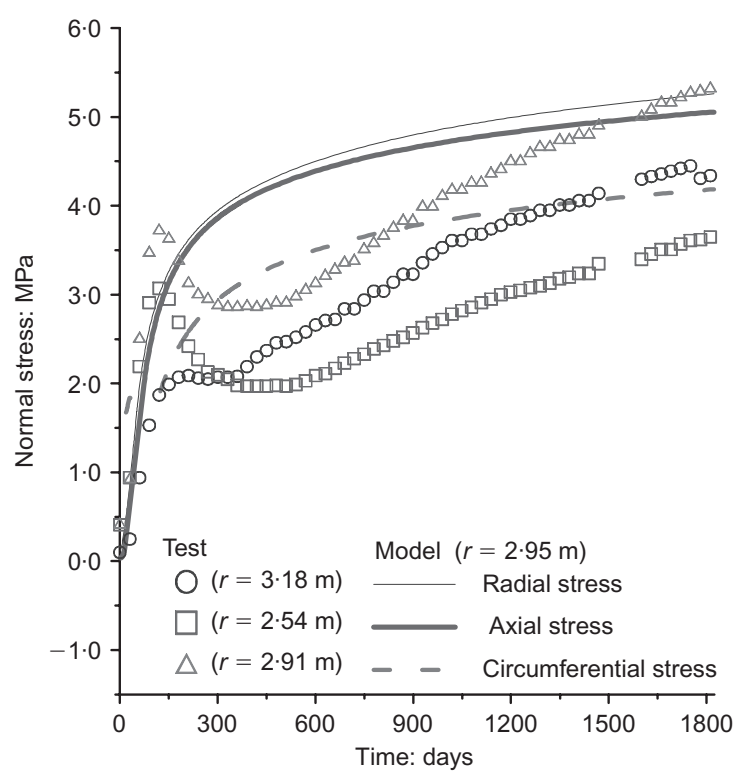

(a)

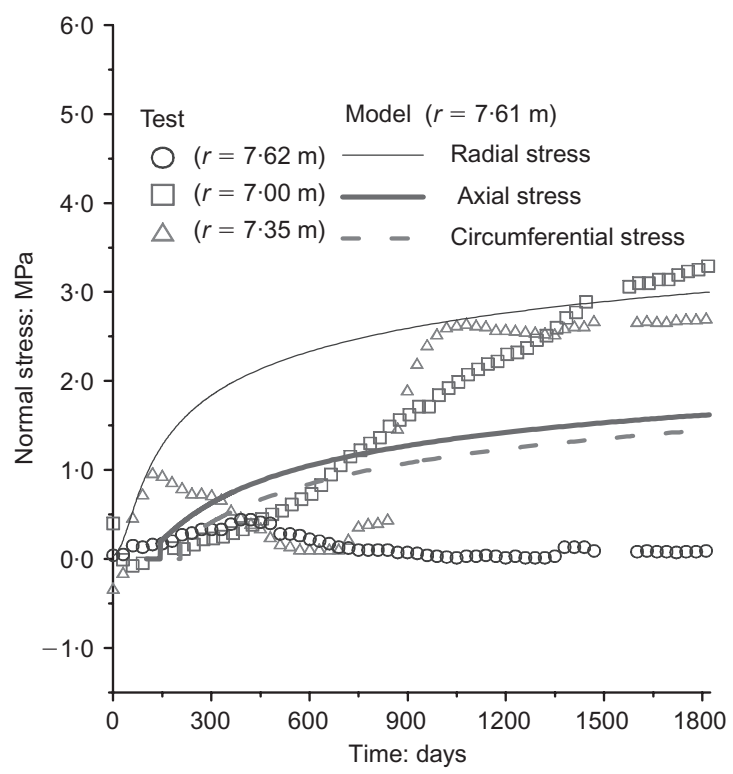

(b)

Fig. 23. Evolution of total stresses in granite, section borehole SG2, observations and computed results: (a) $x=$ 9.14 m; (b) $x=9.22 \mathrm{~m}$

Figure 29 shows the all measured values of water content and dry density as a function of distance to the tunnel axis for a section near the centre of Heater 1: it is therefore representative of a hot region of the test. It can be seen that, as expected, water content increases as the rock is approached, consistent with the process of natural hydration from the rock. It is also interesting to observe that the part of the barrier close to the heater is still below its initial value of water content, a consequence of the strong drying that has occurred in this area. Although a certain amount of water has already reached the inner region, it is still insufficient, after five years, to compensate for the initial drying. It is also noticeable that the barrier as a whole is very far from full saturation at the end of the heating stage. The distribution of dry density also shows the expected patterns. Close to the rock the clay has expanded, exhibiting values of dry density well below its initial value. In contrast, in the zone near the heater the dry density has increased. Because of the confined nature of the test, the variation of dry density in the inner part is compensated for by the reduction of dry density in the outer part. The change of dry density (i.e. porosity) is the combined effect of expansion due to temperature increase (thermal effect), suction changes (hydraulic effect) and stress increase due to the development of swelling pressure (mechanical effect).

Water content and dry density values are also plotted for a cool section (Fig. 30), where the temperature increase is very limited. There are some differences in the patterns of observations. Water content again increases as the rock is approached, but now there is also a net (but small) gain of water content near the centre of the tunnel. There has been no drying in this region, but the amount of hydration is very small, even after five years, because of the thickness of the barrier in this section. The dry density also shows a significant reduction close to the rock, but a somewhat smaller increase in the inner part, where the change appears to be more uniform. Again, the net volume change of the section is quite small.

The results of the numerical analysis show very good agreement with the measurements: in this case the computed results are obviously predictions. The patterns of the hot and cool sections are reproduced very well, and the quantitative agreement between observations and predictions is quite close. To obtain those predictions, the numerical analysis has simulated the cooling stage and the excavation performed prior to sampling. Dismantling operations lasted for two months; the time required to reach each particular sampling section has also been incorporated in the analysis.

\section{CONCLUDING REMARKS}

A large-scale in situ heating test has been performed to simulate the conditions of high-level radioactive waste disposal in a deep geological repository excavated in granite. The heaters mimicking the thermal effects of nuclear waste are surrounded by an engineered barrier made up of compacted swelling clay. The test has provided, for a period of up to five years, a large amount of information concerning 


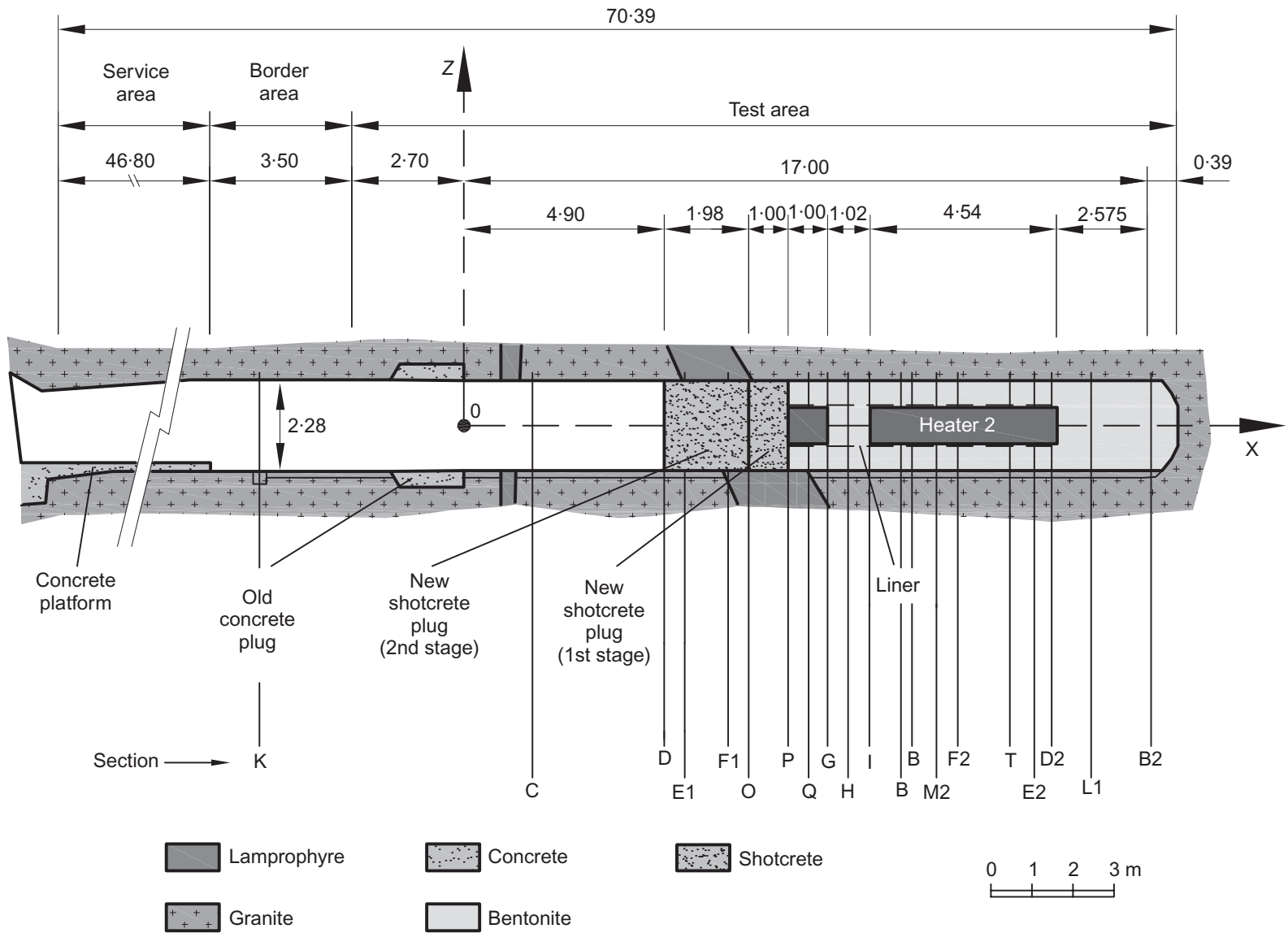

Fig. 24. State of experiment after partial dismantling

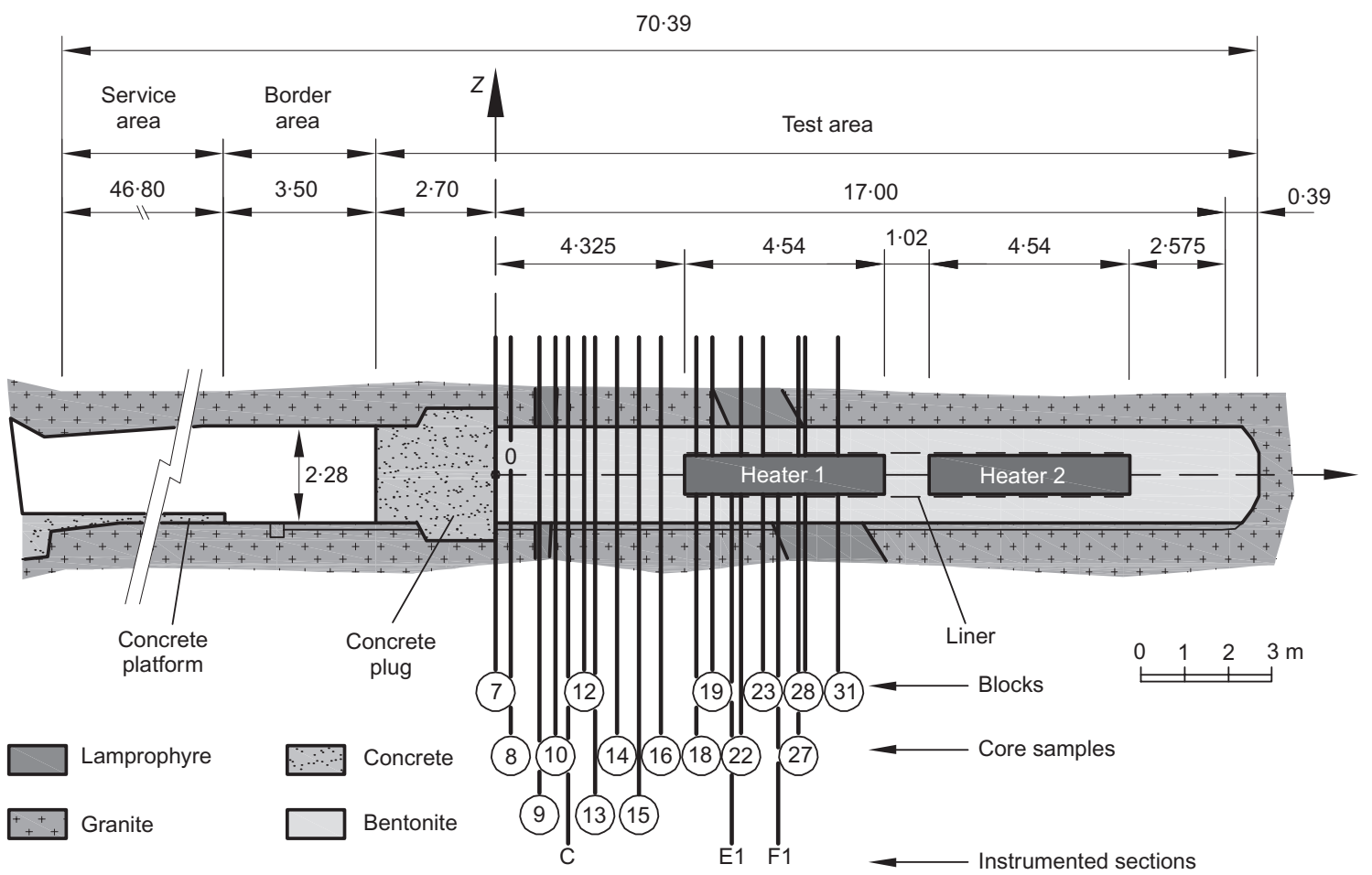

Fig. 25. Location of sampling sections

the thermo-hydro-mechanical behaviour of the bentonite barrier and of the adjacent rock. The progress of hydration, the effects of heating, vapour transport and development of swelling pressures have been identified as the major interact- ing phenomena underlying the observed patterns of behaviour. After a five-year heating stage the experiment has been partially dismantled, allowing direct observation of the final state of the clay barrier. 


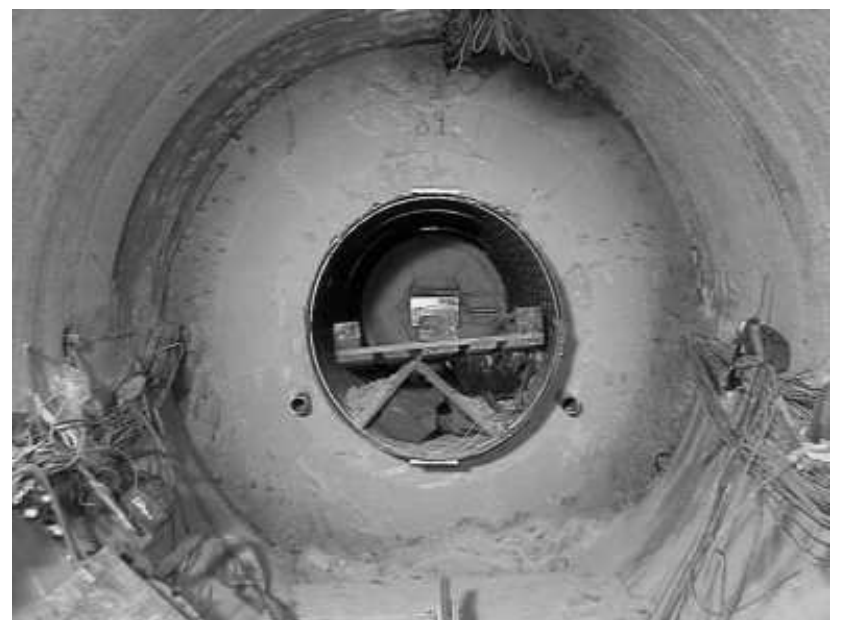

Fig. 26. State of the bentonite barrier after five years of heating and hydration

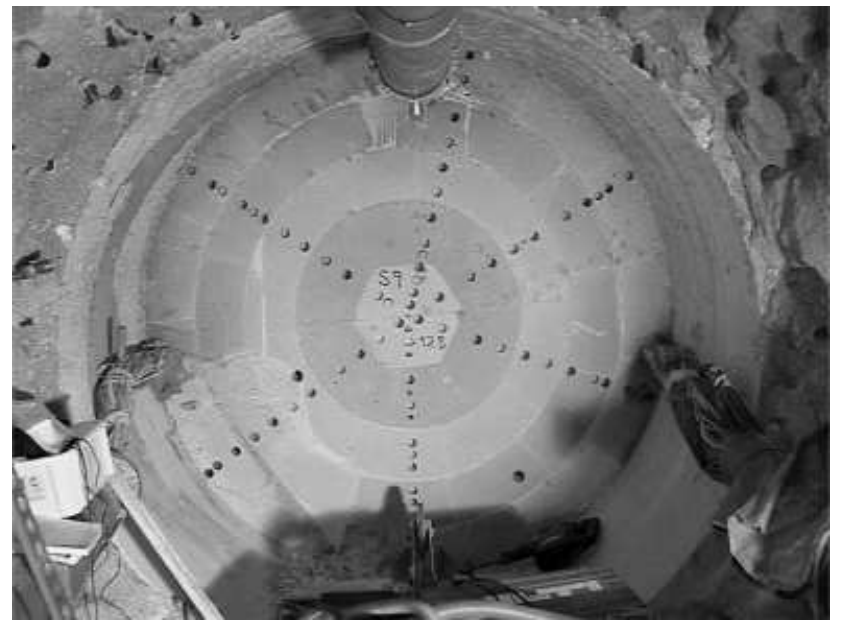

Fig. 27. Bentonite sampling during dismantling: section 9

An adequate interpretation of the test requires appropriate coupled numerical analysis to be performed. A coupled THM formulation has been presented that incorporates the relevant processes involved in the problem under consideration. The general balance equations are complemented by constitutive laws and equilibrium restrictions describing the specific characteristics of the phenomena considered. Although the number of parameters required to define the numerical problem is quite high, it has been possible to determine them on the basis of an extensive programme of field and laboratory tests. The numerical model was developed before and during the very early stages of the test: therefore the model computations largely represent a predictive exercise.

Comparing the observations gathered during the performance of the test with the results of the numerical analysis, it can be concluded that the formulation and associated computer code are able to reproduce well the main observed features of the THM behaviour of the test. Indeed, quantitative agreement is very satisfactory for a large number of variables. At the outset of the analysis it was expected that a more refined modelling, including explicit consideration of the gaps between blocks and some localised water inflow areas, would be required. However, a satisfactory represent-

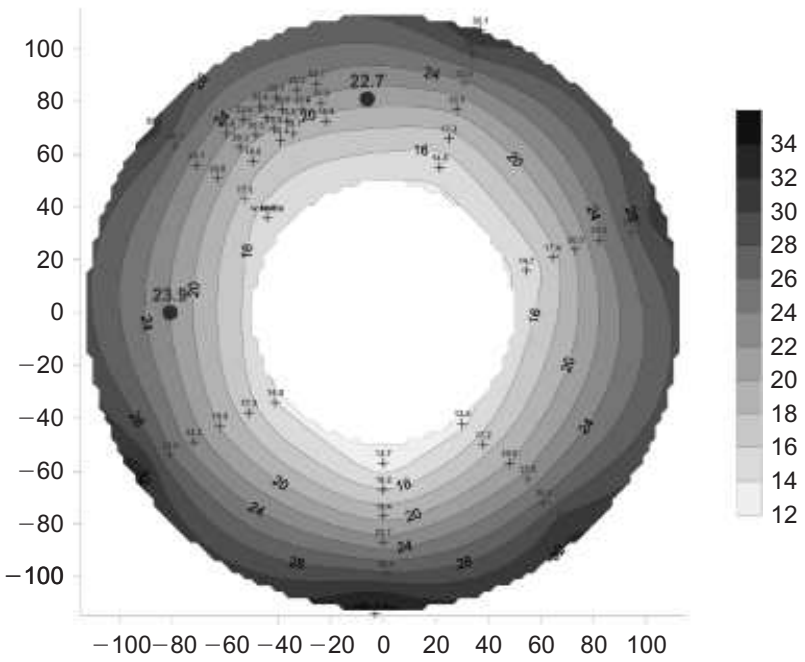

(a)

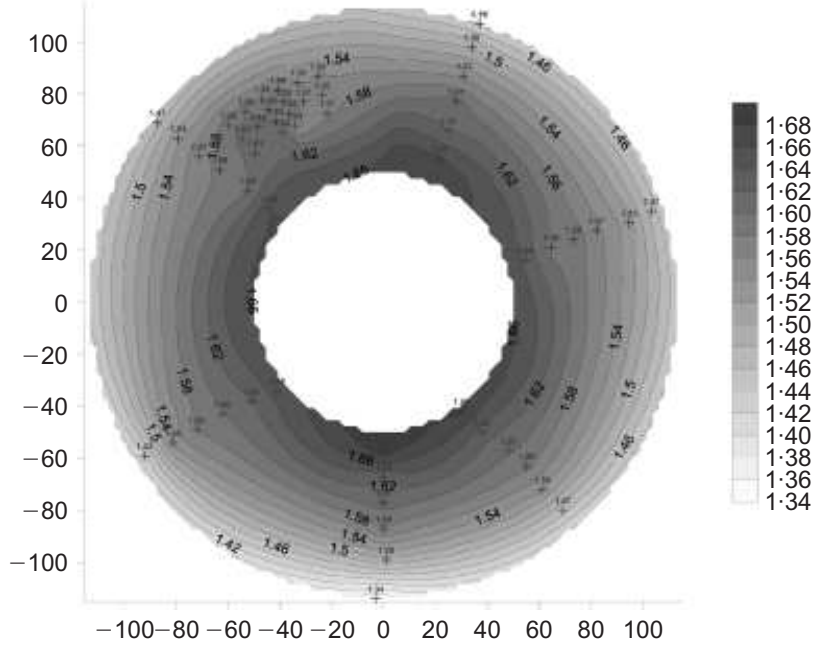

(b)

Fig. 28. Contours of (a) water content and (b) dry density measured during dismantling: section 27

ation of the tests was achieved without introducing these additional complexities. It is likely that the gaps closed at the early stages of the test owing to local swelling of the bentonite blocks. Indeed, direct observations during dismantling confirmed closure of the joints between bentonite blocks and of the barrier/rock gap.

It can therefore be stated that the formulation is able to capture the main phenomena involved as well as their interactions, and, in addition, it has a good predictive power. This is especially noteworthy as the test has been carried out in a natural environment, with the uncertainties and heterogeneities inevitably associated with natural systems. Information obtained during dismantling has provided further evidence of the predictive capabilities of the numerical model. In this way, confidence in the use of these computational tools for the long-term prediction of THM problems associated with nuclear waste disposal is significantly enhanced. Indeed, this predictive capability can probably be extended to other geotechnical problems involving non-isothermal conditions. However, it is possible that, when longer periods are considered, other phenomena may start playing a more significant role, such as thermo-osmosis, chemical effects or the double-porosity fabric of the compacted bentonite. This remains 


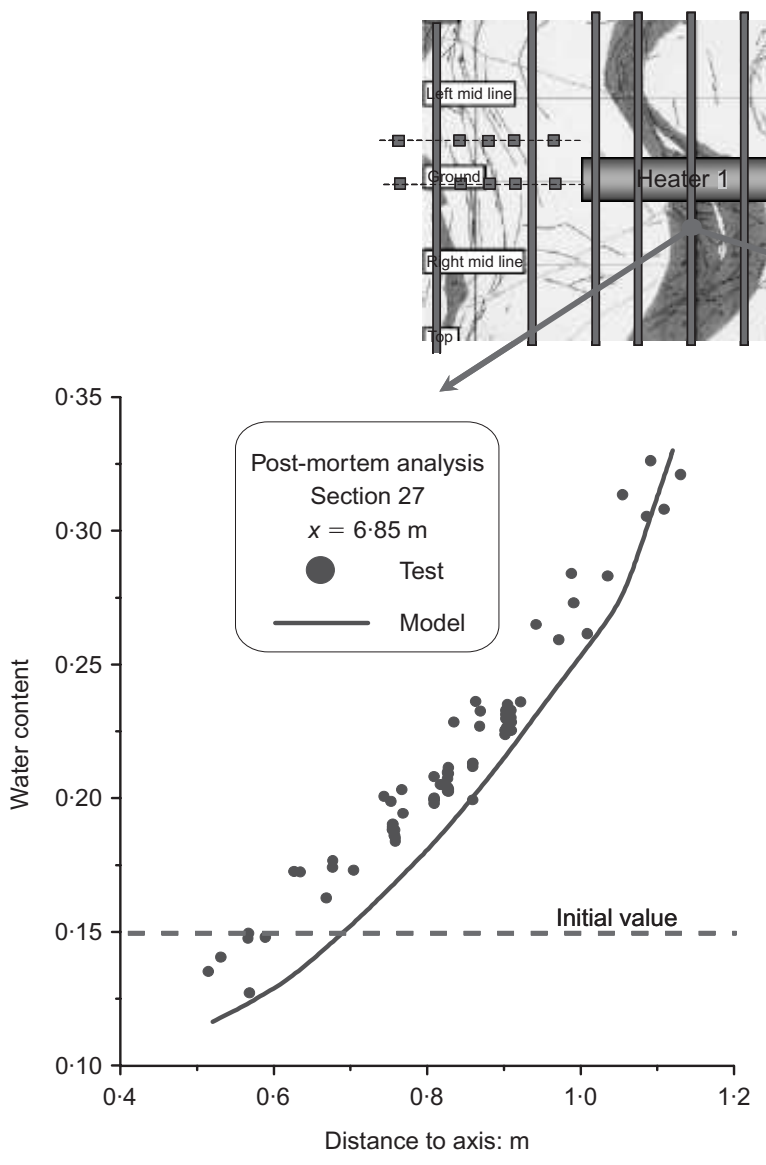

(a)

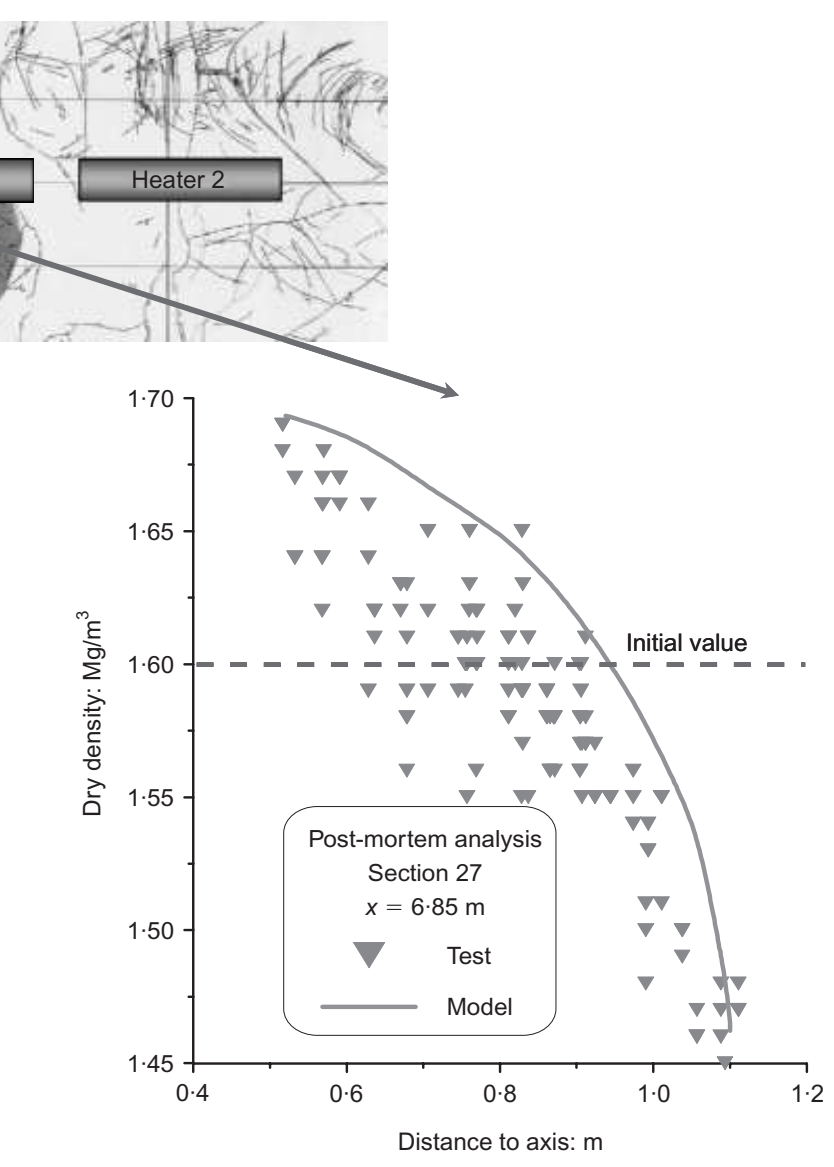

(b)

Fig. 29. Values of (a) water content and (b) dry density measured during dismantling in section 27 (hot section): observations and computed results

an area of active research at present (Sánchez et al., 2007; Gens et al., 2008).

\section{ACKNOWLEDGEMENTS}

The authors gratefully acknowledge the financial and technical support of ENRESA and the Commission of the European Union. We also thank AITEMIN and CIEMAT for their technical assistance and useful discussions.

\section{APPENDIX}

The mechanical constitutive model adopted is based on the Barcelona Basic Model, BBM (Alonso et al., 1990). The BBM considers two independent stress variables to model unsaturated soil behaviour: net stress $(\boldsymbol{\sigma})$, defined as the excess of the total stresses over the gas pressure $\left(\boldsymbol{\sigma}_{\mathrm{t}}-\boldsymbol{I} p_{\mathrm{g}}\right)$; and the matric suction $(s)$. The BBM is an elasto-plastic model in which the yield surface depends not only on stresses (and history variables) but also on matric suction and temperature. The BBM yield surface $\left(F_{\mathrm{LC}}\right)$ is expressed as

$$
F_{\mathrm{LC}}=3 J^{2}-\left[\frac{g(\theta)}{g\left(-30^{\circ}\right)}\right]^{2} M^{2}\left(p+p_{\mathrm{s}}\right)\left(p_{0}-p\right)=0
$$

where $p$ is the mean net stress, $J$ is the square root of the second invariant of deviatoric stress tensor, $M$ is the slope of the critical state, $p_{0}$ is the apparent unsaturated preconsolidation pressure, $g(\theta)$ is a function of Lode's angle $\theta$, and $p_{\mathrm{s}}$ considers the dependence of shear strength on suction and temperature.

The variation of compressibility $\lambda(s)$ with suction is given by

$$
\lambda(s)=\lambda(o)[(1-r) \exp (-\beta s)+r]
$$

where $\lambda(o)$ is the compressibility of the saturated material, and $r$ and $\beta$ are material parameters defining the shape of the LC yield surface. The flow rule can be defined as

$$
\varepsilon_{\mathrm{vp}}^{\mathrm{p}}=\mu_{1} n_{\mathrm{p}}, \quad \varepsilon_{\mathrm{s}}^{\mathrm{p}}=\mu_{1} n_{\mathrm{q}}
$$

and

$$
n_{\mathrm{p}}=1 ; n_{\mathrm{q}}=\frac{2 q \alpha}{M^{2}\left(2 p+p_{\mathrm{s}}-p_{0}\right)}
$$

where $\alpha$ is a material parameter that controls the degree of nonassociativity.

The hardening law is expressed as a rate relation between the volumetric plastic strain $\left(\varepsilon_{\mathrm{v}}^{\mathrm{p}}\right)$ and the saturated isotropic preconsolidation stress $\left(p_{0}^{*}\right)$, according to

$$
\dot{p}_{0}^{*}=\frac{1+e}{\lambda(o)-\kappa} p_{0}^{*} \dot{\varepsilon}_{\mathrm{v}}^{\mathrm{p}}
$$

where $e$ is void ratio, and $\kappa$ is the elastic stiffness parameter for changes in net mean stress.

The original elastic formulation of the BBM is modified in order to reproduce the observed expansive behaviour of the bentonite. The elastic model adopted is

$$
\begin{aligned}
& \dot{\varepsilon}_{\mathrm{v}}^{\mathrm{e}}=\frac{\kappa}{1+e} \frac{\dot{p}}{p}+\frac{\kappa_{\mathrm{s}}}{1+e} \frac{\dot{s}}{s+p_{\mathrm{at}}}+\left(\alpha_{0}+\alpha_{2} \Delta T\right) \dot{T} \\
& \dot{\varepsilon}_{\mathrm{s}}^{\mathrm{e}}=\frac{\dot{J}}{G_{\mathrm{t}}}
\end{aligned}
$$

where $\varepsilon_{\mathrm{v}}^{\mathrm{e}}$ and $\varepsilon_{\mathrm{s}}^{\mathrm{e}}$ are the volumetric and deviatoric components of the elastic strain respectively; $\kappa_{\mathrm{s}}$ is the elastic stiffness parameter for changes in suction; $\alpha_{0}$ and $\alpha_{2}$ are model parameters; $\Delta T$ is the temperature difference with respect to an arbitrary reference temperature $T_{0}$; and $G_{\mathrm{t}}$ is the shear modulus. The elastic stiffness 


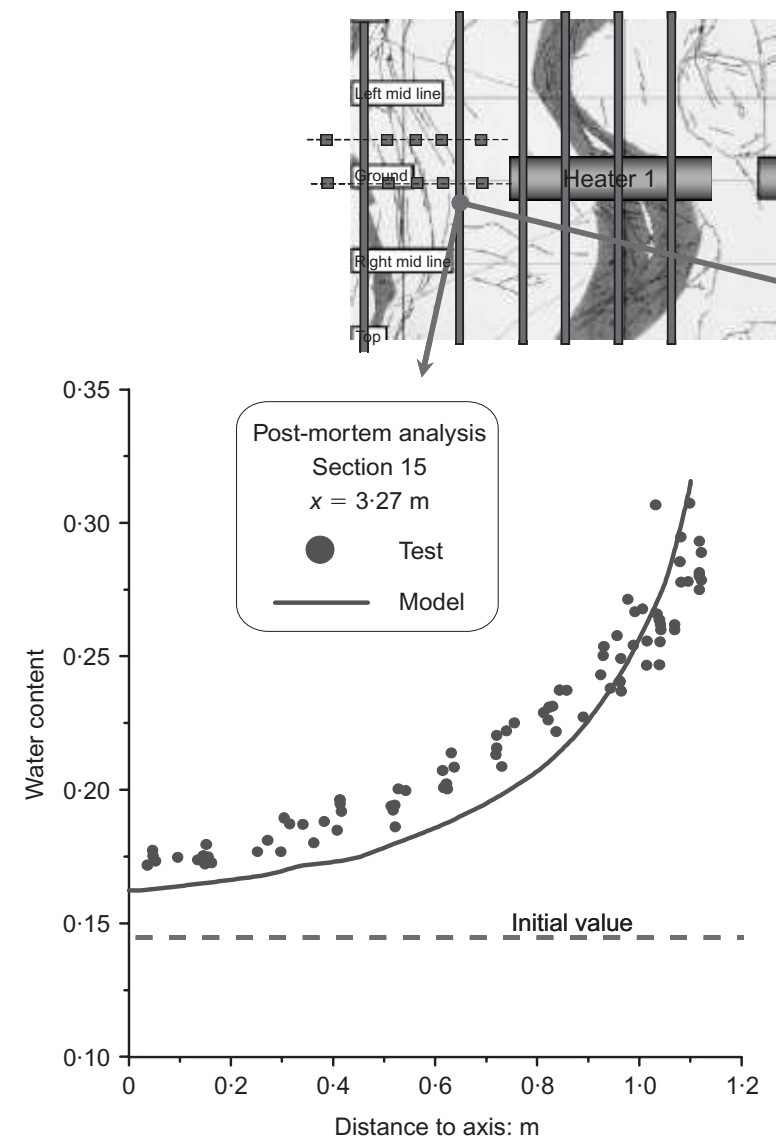

(a)

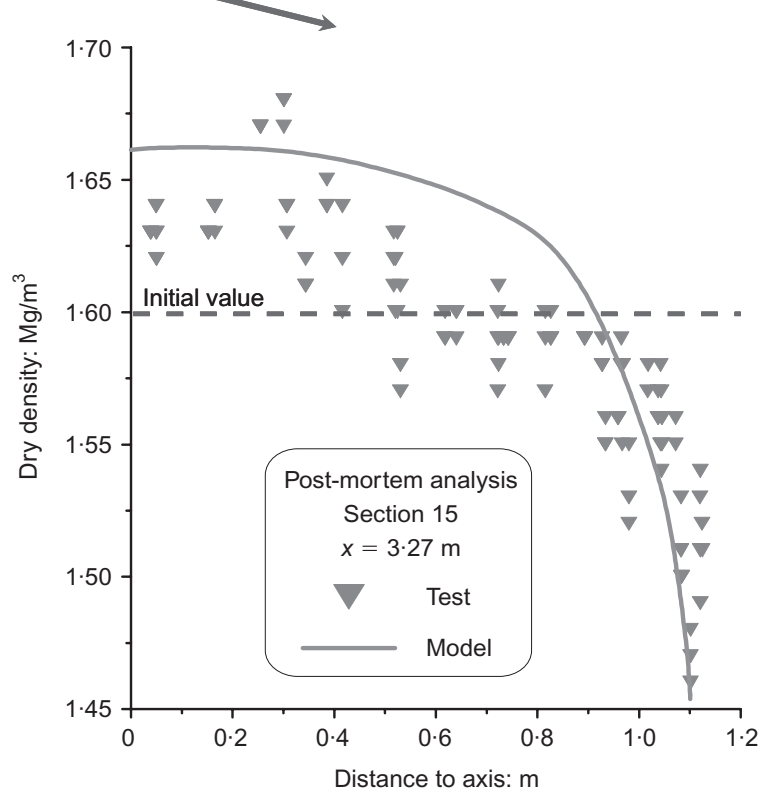

(b)

Fig. 30. Values of (a) water content and (b) dry density measured during dismantling in section 15 (cool section): observations and computed results

parameter for changes in net mean stress depends on suction, according to

$$
\kappa=\kappa_{0}\left(1+\alpha_{\mathrm{s}} s\right)
$$

where $\kappa_{0}$ is the elastic stiffness parameter in saturated conditions, and $\alpha_{\mathrm{s}}$ is a model parameter. The elastic stiffness parameter for changes in suction depends in turn on mean stress, as

$$
\kappa_{\mathrm{s}}=\kappa_{\mathrm{s} 0}\left(1+\alpha_{\mathrm{sp}} \ln p / p_{\text {ref }}\right)
$$

where $\kappa_{\mathrm{s} 0}$ and $\alpha_{\mathrm{sp}}$ are model parameters.

\section{NOTATION}

$\boldsymbol{b}$ vector of body forces

$D$ matrix describing the relationship between increments of strains and stresses

$\boldsymbol{D}_{\mathrm{g}}^{\mathrm{W}} \quad$ vapour diffusion in Fick's law

$D_{\mathrm{m}}^{\mathrm{W}}$ molecular diffusion coefficient of vapour in open air

$\mathrm{D}_{\mathrm{s}}(\cdot) / \mathrm{D} t$ material derivative with respect to the solid

$E_{\alpha} \quad$ specific internal energy of $\alpha$ phase $(\alpha=\mathrm{s}, 1, \mathrm{~g})$

$e$ void ratio

$F_{\mathrm{LC}} \quad$ BBM yield surface

$f^{i}$ external supply of $i$ species $(i=\mathrm{w}$, a)

$f^{\mathrm{Q}}$ external supply of energy

$f_{\mathrm{d}}$ auxiliary function in retention curve

$\boldsymbol{g}$ gravity vector

$g$ Lode angle function in the deviatoric plane

$G_{\mathrm{t}}$ shear modulus

$H$ Henry's constant

$\boldsymbol{h}$ vector that relates changes of stresses to changes in suction

I identity matrix

$i_{\alpha}^{i} \quad$ non-advective mass flux $(i=\mathrm{w}, \mathrm{a} ; \alpha=1, \mathrm{~g})$ $i_{\mathrm{c}}$ conductive heat flux

$J$ second stress invariant of deviatoric stress tensor

$j_{\mathrm{E} \alpha} \quad$ advective energy flux in $\alpha$ phase with respect to a fixed reference system $(\alpha=\mathrm{s}, 1, \mathrm{~g})$

$j_{\alpha}^{i}$ total mass flux of $i$ species in $\alpha$ phase with respect to a fixed reference system ( $i=\mathrm{w}, \mathrm{a} ; \alpha=1, \mathrm{~g})$

$j_{\alpha}^{i}$ total mass flux of $i$ species in $\alpha$ phase with respect to solid phase ( $i=\mathrm{w}, \mathrm{a} ; \alpha=1, \mathrm{~g})$

$\boldsymbol{K}_{\alpha}$ permeability tensor $(\alpha=1, \mathrm{~g})$

$K$ bulk modulus

$\boldsymbol{k}$ intrinsic permeability tensor

$k$ parameter describing the increase of cohesion with suction

$k_{\mathrm{r} \alpha} \quad \alpha$ phase relative permeability $(\alpha=1, \mathrm{~g})$

LC loading-collapse yield surface in the BBM model

$M$ slope of critical-state line

$M_{i} \quad$ molecular mass of $i$ species $(i=\mathrm{w}$, a)

$n$ parameter in relative permeability law

$P_{\text {at }}$ atmospheric pressure

$P_{\alpha}$ pressure of $\alpha$ phase $(\alpha=l, g)$

$P_{0}, P_{\mathrm{d}}$ retention curve parameters

$p$ mean net stress

$p_{\mathrm{c}}$ reference stress in BBM model

$p_{\mathrm{s}}$ tensile strength

$p_{\mathrm{v}} \quad$ vapour pressure

$p_{\text {ref }}$ reference pressure in stiffness-suction relationship

$p_{\mathrm{v}}^{0} \quad$ vapour pressure at zero suction

$p_{0}$ net mean yield stress at current suction and temperature

$p_{0}^{*} \quad$ net mean yield stress for saturated conditions at reference temperature

$q_{\alpha}$ volumetric flux in $\alpha$ phase with respect to the solid $(\alpha=l, g)$

$R$ universal gas constant

RH relative humidity 
$r$ parameter defining maximum soil stiffness in BBM model

$S_{\alpha} \quad$ volumetric fraction of pore volume occupied by $\alpha$ phase $(\alpha=1, \mathrm{~g})$

$S_{\mathrm{el}}$ effective degree of saturation

$S_{\mathrm{lr}}$ residual saturation

$S_{\mathrm{ls}}$ maximum saturation

$s$ suction

$T$ temperature

$t$ time

$\boldsymbol{u}$ solid displacement vector

$\alpha$ parameter in flow rule in BBM model

$\alpha_{0}, \alpha_{2}$ parameters that relate elastic volumetric strain and temperature changes

$\alpha_{\mathrm{s}}$ parameter that relates suction and elastic stiffness

$\alpha_{\mathrm{sp}}$ parameter that relates mean stress and elastic stiffness

$\boldsymbol{\beta}$ vector that relates stresses and temperature changes

$\beta$ parameter defining shape of LC yield surface in BBM model

$\varepsilon_{\mathrm{v}}^{\mathrm{e}}, \varepsilon_{\mathrm{v}}^{\mathrm{p}} \quad$ volumetric elastic and plastic strains

$\varepsilon_{\mathrm{s}}^{\mathrm{v}}, \varepsilon_{\mathrm{s}}^{\mathrm{p}} \quad$ deviatoric elastic and plastic strains

$\zeta$ parameter controlling rate of increase of soil stiffness with suction

$\theta$ Lode's angle

$\theta_{\alpha}^{i} \quad\left(=\rho_{\alpha} \omega_{\alpha}^{i}\right)$ mass of $i$ species in $\alpha$ phase per unit volume of $\alpha$ phase $(i=\mathrm{w}, \mathrm{a} ; \alpha=1, \mathrm{~g})$

$\theta_{\mathrm{s}}$ density of solid phase

$\kappa$ elastic stiffness for changes in mean stress

$\kappa_{0}$ elastic stiffness for changes in mean stress in saturated conditions

$\kappa_{\mathrm{S}} \quad$ elastic stiffness for changes in suction

$\kappa_{\mathrm{s} 0}$ elastic stiffness for changes in suction at reference pressure $\left(p_{\text {ref }}\right)$

$\lambda(s) \quad$ stiffness parameter for changes in net mean stress for virgin states of soil at suction $s$

$\lambda_{\text {sat }}, \lambda_{\text {dry }}$ thermal conductivity in saturated and dry states

$\lambda_{0}, \lambda_{\mathrm{d}}$ retention curve parameters

$\mu$ Poisson's coefficient

$\mu_{\alpha}$ dynamic viscosity of $\alpha$ phase $(\alpha=1, \mathrm{~g})$

$\nabla$ gradient vector

$\rho$ density

$\rho_{\alpha}$ density of $\alpha$ phase $(\alpha=\mathrm{s}, 1, \mathrm{~g})$

$\boldsymbol{\sigma}_{\tau}$ total stress vector

$\boldsymbol{\sigma}$ net stress vector $\left(=\boldsymbol{\sigma}_{\tau} \boldsymbol{I} P_{\mathrm{g}}\right)$

$\tau$ tortuosity

$\phi$ porosity

$\psi$ total suction

$\omega_{\alpha}^{i} \quad$ mass fraction of $i$ species in $\alpha$ phase $(i=\mathrm{w}, \mathrm{a} ; \alpha=1, \mathrm{~g})$

\section{REFERENCES}

Alonso, E. E. \& Alcoverro, J. (2005). The FEBEX test as a benchmark case for THM modelling: historical perspective and lessons learnt. In Advances in understanding engineered clay barriers (eds E. E. Alonso and A. Ledesma), pp. 3-19. London: Taylor \& Francis.

Alonso, E. E., Gens, A. \& Josa, A. (1990). A constitutive model for partially saturated soils. Géotechnique 40, No. 3, 405-430.

Bárcena, I., Fuentes-Castillana, J. \& Garcia-Siñeriz, J. (2003). Dismantling of heater no. 1 at the FEBEX in-situ test: Descriptions of operations, Technical Publication 09/2003. Madrid: Enresa.

Dixon, D., Chandler, N., Graham, J. \& Gray, M. N. (2002). Two large-scale sealing tests conducted at Atomic Energy of Canada's underground research laboratory: the buffer-container experiment and the isothermal test. Can. Geotech. J. 39, No. 3, 503-518.

Frieg, B. \& Vomvoris, S. (1994). Investigation of hydraulic parameters in the saturated and unsaturated zone of the ventilation drift, Technical Report 93-10. Baden: Nagra.

Gawin, D., Baggio, P. \& Schrefler, B. A. (1995). Coupled heat, water and gas flow in deformable porous media. Int. J. Numer. Meth. Fluids 20, Nos 8-9, 969-987.

Gens, A. (2003). The role of geotechnical engineering in nuclear energy utilisation: special lecture. Proc. 13th. Eur. Conf. Soil Mech. Geotech. Engng, Prague 3, 25-67.

Gens, A. (2007). Soil-environment interactions in geotechnical engineering: The 47th Rankine Lecture. Géotechnique (in preparation for print).

Gens, A. \& Olivella, S. (2000). Non isothermal multiphase flow in deformable porous media: coupled formulation and application to nuclear waste disposal. In Developments in theoretical soil mechanics (eds Smith, D. W. and Carter, J. P.), pp. 619-640. Rotterdam: Balkema.

Gens, A., Garcia-Molina, A. J., Olivella, S., Alonso, E. E. \& Huertas, F. (1998). Analysis of a full scale in situ test simulating repository conditions. Int. J. Numer. Anal. Methods Geomech. 22, No. 7, 515-548.

Gens, A., Guimarães, L. Do N., Garcia-Molina, A. \& Alonso, E. E. (2002). Factors controlling rock-clay buffer interaction in a radioactive waste repository. Engng Geol. 64, Nos 2-3, 297308.

Gens, A., Vaunat, J., Garitte, B. \& Wileveau, Y. (2007). In situ behaviour of a stiff layered clay subject to thermal loading observations and interpretation. Géotechnique 57, No. 2, 207228.

Gens, A., Guimarães, L. Do N., Sánchez, M. \& Sheng, D. (2008). Developments in modelling the generalised behaviour of unsaturated soils: Keynote lecture. In Unsaturated soils: Advances in geo-engineering (eds D. Toll, C. E. Augarde, D. Gallipoli and S. J. Wheeler), pp. 53-61. London: Taylor \& Francis.

Huertas, F., Fariña, P., Farias. J., García-Siñériz, J. L., Villar, M. V., Fernández, A. M., Martín, P. L., Elorza, F. J., Gens, A., Sánchez, M., Lloret, A., Samper, J. \& Martínez, M. A. (2006). Full-scale engineered barrier experiment: Updated final report, Technical Publication 05-0/2006. Madrid: Enresa.

Keusen, H. R., Ganguin, J., Schuler, P. \& Buletti, M. (1989). Grimsel test site: Geology, Technical Report 87-14E. Baden: Nagra.

Lloret, A., Villar, M. V., Sánchez, M., Gens, A., Pintado, X. \& Alonso, E. (2003). Mechanical behaviour of heavily compacted bentonite under high suction changes. Géotechnique 53, No. 1, $27-40$.

Olivella, S., Carrera, J., Gens, A. \& Alonso, E. E. (1994). Nonisothermal multiphase flow of brine and gas through saline media. Transp. Porous Media 15, No. 3, 271-293.

Olivella, S., Gens, A. Carrera, J. \& Alonso, E. E. (1996). Numerical formulation for a simulator 'CODE_BRIGHT' for the coupled analysis of saline media. Engng Comput. 13, No. 7, 87-112.

Ortuño, F., Carretero, G., Martínez-Landa, L. \& Carrera, J. (2005). Hydraulic characterisation of the FEBEX granite: test performance and field interpretation. In Advances in understanding engineered clay barriers (eds E. E. Alonso and A. Ledesma), pp. 133-141. London: Taylor \& Francis.

Pintado, X. (2002). Caracterización del comportamiento termo-hidromecánico de arcillas expansivas. $\mathrm{PhD}$ thesis, Geotechnical Engineering Department, Technical University of Catalunya, Spain.

Pintado, X., Ledesma, A. \& Lloret, A. (2002). Backanalysis of thermohydraulic bentonite properties from laboratory tests. Engng Geol. 64, Nos 2-3, 91-115.

Pusch, R., Borgesson, L. \& Ramqvist, G. (1985). Final report of the mass buffer test-volume II: Test results, Stripa Project 85/ 12. Stockholm: SKB.

Romero, E., Villar, M. V. \& Lloret, A. (2005). Thermo-hydromechanical behaviour of two heavily overconsolidated clays. Engng Geol. 81, No. 3, 255-268.

Sánchez, M. \& Gens, A. (2006). FEBEX project: Final report on thermo-hydro-mechanical modelling, Technical Publication 05-2/ 2006. Madrid: Enresa.

Sánchez, M., Villar, M. V., Lloret, A. \& Gens, A. (2007). Analysis of the expansive clay hydration under low hydraulic gradient. In Experimental unsaturated soil mechanics, Springer Proceedings in Physics 112, pp. 309-318. Berlin, Springer.

Selvadurai, A. P.S. (1997). Hydro-thermo-mechanics of engineered clay barriers and geological barriers. Engng Geol. 47, No. 4, 311-312.

Thomas, H. R. \& He, Y. (1995). An analysis of coupled heat, moisture and air transfer in a deformable unsaturated soil. Géotechnique 45, No. 4, 677-689.

van Genuchten, R. (1978). Calculating the unsaturated hydraulic 
permeability conductivity with a new closed-form analytical model. Water Resour. Res. 37, No. 11, 21-28.

Villar, M. V. (2002). Thermo-hydro-mechanical characterisation of a bentonite from Cabo de Gata: A study applied to the use of bentonite as sealing material in high-level radioactive waste repositories, Technical Publication 01/2002. Madrid: Enresa.

Villar, M. V. \& Lloret, A. (2004). Influence of temperature on the hydro-mechanical behaviour of a compacted bentonite. Appl. Clay Sci. 26, Nos 1-4, 337-350.

Villar, M. V., García-Siñeriz, J. L., Bárcena, I. \& Lloret, A. (2005).
State of the bentonite barrier after five years operation of an in situ test simulating a high level radioactive waste repository. Engng Geol. 80, Nos 3-4, 175-198.

Volckaert, G., Bernier, F., Alosnos, E., Gens, A., Samper, J., Villar, M. V., Martin, P. L., Cuevas, J., Campos, R., Thomas, H. R., Imbert, C. \& Zingarelli, V. (1996). Thermal-hydraulic-mechanical and geochemical behaviour of the clay barrier in radioactive waste repositories (model development and validation), Nuclear Science and Technology, EUR 16744. Luxembourg: Commission of the European Communities. 